\title{
VHCF Behavior of Welded Joints with HFMI Treatment under Moisture Conditions
}

\author{
The fatigue behaviors of welded steel structures were tested in two different \\ environments and treatment conditions
}

BY Z. GAO, D. WANG, B. GONG, C. DENG, S. WU, AND H. ZHANG

\begin{abstract}
Fatigue tests of cruciform welded joints made of Q355B steel at very-high-cycle fatigue (VHCF) regimes were carried out on as-welded specimens using highfrequency mechanical impact (HFMI) treatment in dry air and water-spray environments, respectively. The influence of the environment on fatigue life was more obvious in the VHCF regime. It was found that S-N curves became flat over the range of $10^{6}-10^{8}$ cycles for as-welded specimens, while a continuously decreasing $\mathrm{S}-\mathrm{N}$ curve existed for HFMI-treated specimens. Fatigue cracks initiated from the weld toe of the as-welded specimens in dry air and water-spray environments. Due to residual stress, the crack initiation site transition of HFMI-treated specimens from the weld toe to the weld root and base metal was observed at lower stress levels. Moreover, hydrogen-assisted quasi-cleavage and intergranular fracture were captured using a scanning electron microscope and a hydrogen permeation test.
\end{abstract}

\section{Keywords}

- Welded Joints

- Environmental Effect

- High-Frequency Mechanical Impact (HFMI)

- Residual Stress Distribution

\section{Introduction}

Many sea-crossing steel bridges with designed lives of up to hundreds of years have been built in China since 2000, such as the
Hong Kong-Zhuhai-Macao Bridge and the Hangzhou Bay Bridge. These long bridges were constructed by welding moduli. Therefore, a great quantity of welded joints is subjected to alternating loading, and their in-service lives usually extend into the veryhigh-cycle fatigue (VHCF) regime (around $10^{9}$ cycles). Naturally, this issue is crucial for the in-service integrity of these structural components considering the fatigue reliability and improvement techniques of welded joints in the VHCF regime. The presence of a severe notch effect, nonmetallic inclusions, or microflaws along the fusion line, as well as large tensile residual stresses, usually lead to the relatively short fatigue life of welded joints (Refs.1-3).

Extensive research has been performed on welding residual stress and geometrical discontinuity of welded structures in air (Refs. 4, 5). Moreover, it is well known that sea-crossing steel bridges are inevitably affected by corrosive environments, including high humidity and saline environments, etc. However, there are limited studies on the influence of the environment on fatigue performance during VHCF regimes. It was experimentally found (Refs. 6-8) that the fatigue strength of steel decreases significantly because of corrosive environments, and this effect becomes more significant with the decrease of stress amplitude even in a laboratory air environment containing a certain amount of moisture (Ref. 9). Nevertheless, previous investigations have mainly paid attention to the fatigue crack propagation of welded joints in corrosive environments (Refs. 10-12), and there have been few studies on the influence of the environment on the S-N characteristics of welded structures, especially in the VHCF regime (Refs. 7 and 13). Therefore, it is essential to investigate the influence of the environmental media on the fatigue life of welded structures and take reasonable measures against fatigue failure. In recent years, high-frequency mechanical impact (HFMI) treatment has been extensively applied as a postweld treatment due to its benefits in the reduction of local stress concentration, microstructure refinement, and the introduction of large compressive residual stress at the weld toe (Refs. 14-17). 


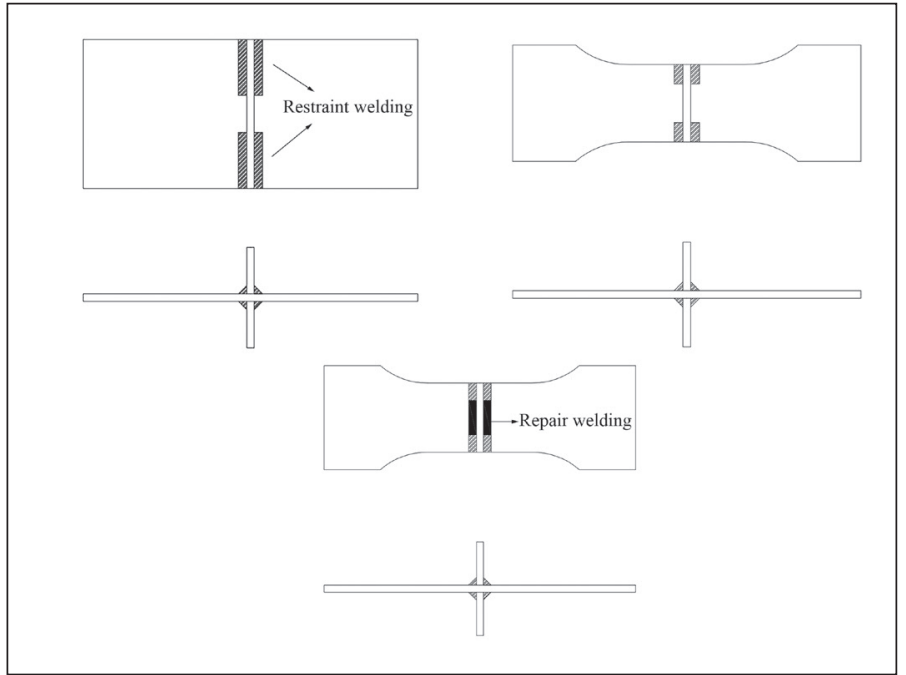

Fig. 1 - Processing sequence of fatigue specimens.

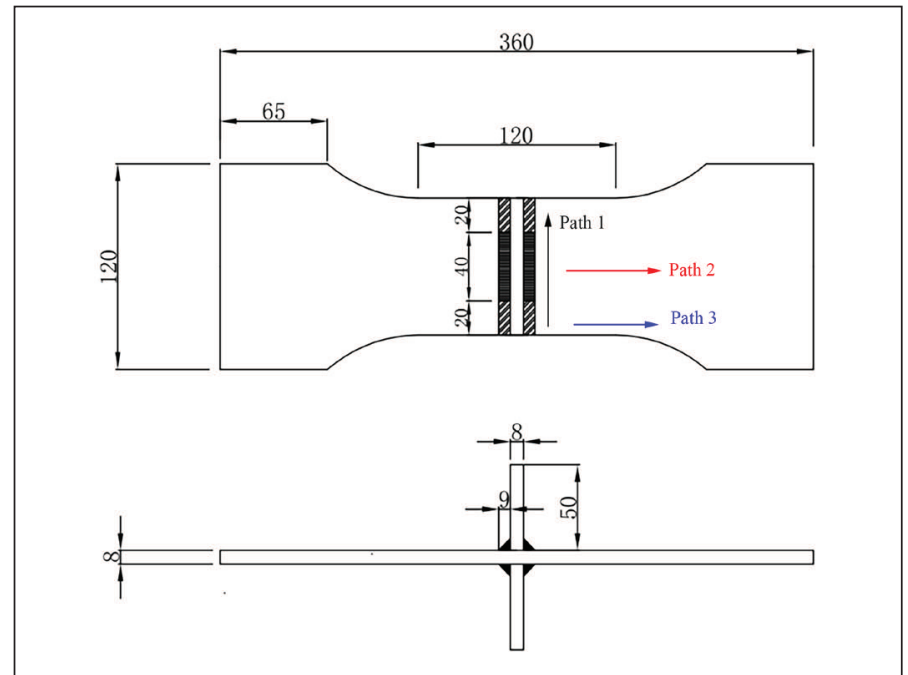

Fig. 2 - Geometry of the fatigue specimen and paths to the residual stress measurement (all dimensions are in $\mathrm{mm}$ ).

Table 1 - Chemical Compositions of Materials, wt-\%

\begin{tabular}{cccccccccc}
\hline Material & C & Si & Mn & Nb & Ti & V & Cr & Ni & \\
Base material & 0.18 & 0.30 & 1.17 & 0.02 & 0.03 & 0.02 & - & - \\
Filler material & 0.05 & 0.36 & 1.07 & - & 0.05 & - & 0.05 & 0.04 & 0.03
\end{tabular}

Table 2 - Mechanical Properties of Materials

\begin{tabular}{|cccc}
\hline Material & $\begin{array}{c}\text { Yield } \\
\text { Strength } \\
\text { (MPa) }\end{array}$ & $\begin{array}{c}\text { Tensile } \\
\text { Strength } \\
\text { (MPa) }\end{array}$ & $\begin{array}{c}\text { Elongation } \\
\text { Rate } \\
\text { (\%) }\end{array}$ \\
\hline Base material & 350 & 515 & 32 \\
\hline Filler material & 480 & 545 & 28 \\
\hline
\end{tabular}

In this study, the fatigue behaviors of welded steel structures were tested in two different environments (laboratory air and water spray) and two different treated conditions (as-welded and $\mathrm{HFMI}$ ). Additional investigations on the residual stress distribution and fracture surfaces were also conducted to demonstrate the influences of the residual stress distribution and environment on the fatigue crack initiation sites and fatigue life. This paper compares the characteristic S-N curves for as-welded and $\mathrm{HFMI}$-treated joints recommended by the International Institute of Welding (IIW) (Ref. 14) with the experiments conducted in this research.

\section{Experimental Procedure}

\section{Specimen Preparation}

The material used in this research was a Q355B steel plate with a thickness of $8 \mathrm{~mm}$. The filler material was a TME 711 electrode with a diameter of $1.2 \mathrm{~mm}$. The chemical composition and mechanical properties are illustrated in Tables 1 and 2, respectively. To induce and keep the high-welding residual stress, the fatigue specimens were prepared as follows: First, the welded joints were welded to constrain both ends. The specimens were then machined by a computer numerical control cutting machine. Lastly, the middle part of the specimen was welded to induce large welding residual stresses. The restraint and repair welding were both conducted by flux cored arc welding with a carbon dioxide shielding gas. The welding current, voltage, and speed were $210 \mathrm{~A}, 27 \mathrm{~V}$, and 3 $\mathrm{mm} / \mathrm{s}$, respectively. The processing sequence and geometry of fatigue specimens are presented in Figs. 1 and 2, respectively.

\section{HFMI Process Parameter}

The HFMI-treated equipment used for this study was the EPT-TJTM UIT-300. The parameters of impact treatment were as follows: an oscillation frequency of $17.9 \mathrm{kHz}$, a tool-treated speed 


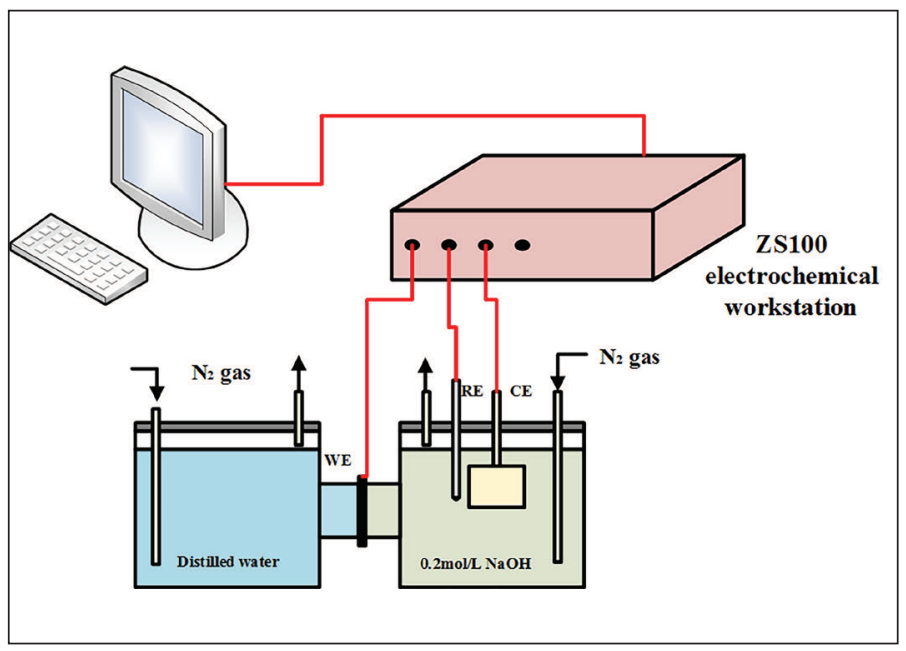

Fig. 3 - Schematic diagram of the Devanathanstachurski permeation cell.

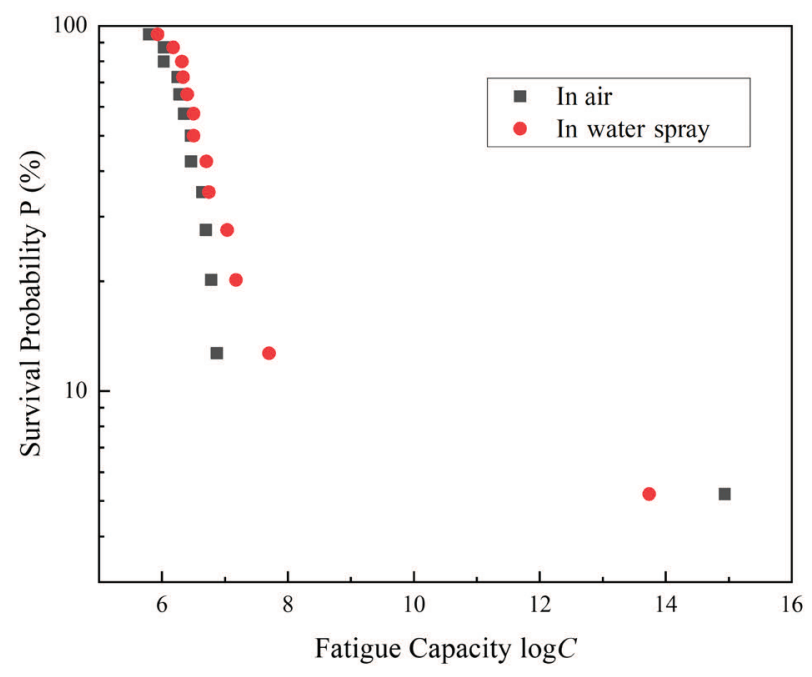

Fig. 5 - Probability plot for heterogeneity of the population.

of $60 \mathrm{~mm} / \mathrm{min}$, a vibration amplitude of $16 \mu \mathrm{m}$, an excitation current of $2 \mathrm{~A}$, and $400 \%$ coverage (the weld toe was treated four times at an angle of $45 \mathrm{deg}$ ).

\section{Residual Stress Measurements}

The evaluation of the distribution of residual stress was conducted using the $x$-ray diffraction method. The transverse residual stresses along the weld toe and perpendicular to the weld line for as-welded and HFMI-treated specimens were determined by the Proto iXRD MG40 x-ray stress analyzer with the sin $2 \psi$ method. The $\psi$ angle was from -25 to $+25 \mathrm{deg}$. The ferrite phase Fe (211) diffraction plane provided by the characteristic $\mathrm{x}$-ray of $\mathrm{Cr}-\mathrm{K} \alpha$ radiation was adopted for the residual stress measurements. The diameter of the irradiated area was $1 \mathrm{~mm}$. The paths of the residual stress measurement are shown in Fig. 2.

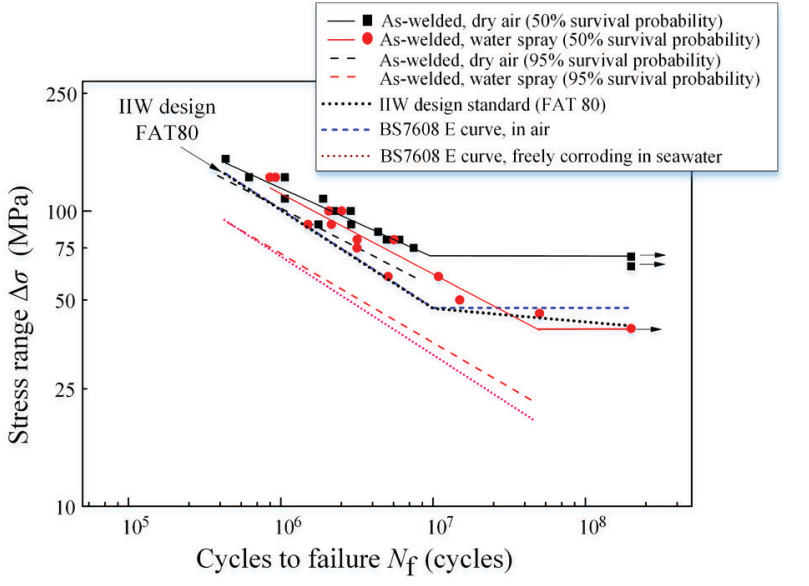

Fig. 4 - S-N fatigue curves of as-welded specimens.

\section{Fatigue Tests}

The fatigue specimens consisted of the following four groups: as-welded in air, as-welded subjected to water spray, HFMI treated in air, and HFMI treated and subjected to water spray. Distilled water with a $\mathrm{pH}$ value of about 6.8 was sprayed continuously with a rate of $100 \mathrm{~mL} / \mathrm{h}$ at room temperature. A resonant highfrequency fatigue machine was used to conduct fatigue tests with the stress ratio $R=0.1$. The testing frequency was about $110 \mathrm{~Hz}$ under constant amplitude loading at ambient temperature. All tests were conducted under uniaxial loading until the crack in the depth direction exceeded the thickness of the specimen or there was no runout at 200 million load cycles as the fatigue failure criterion. The morphology of the fracture surfaces and fatigue initiation sites were analyzed by optical microscope, scanning electron microscopy, and energy spectrum analysis (energydispersive $\mathrm{x}$-ray spectroscopy [EDS]).

\section{Hydrogen Permeation Test}

A hydrogen permeation test was performed to demonstrate the existence of hydrogen in the distilled water environment at ambient temperature. The test was conducted on a Q355B steel with the Devanathan-Stachurski double cells in distilled waterFig. 3. The dimensions of the plate specimen were $30 \times 30 \times 0.5$ $\mathrm{mm}$. The hydrogen was designated to escape from the side of the plate coated with $\mathrm{Ni}$ in a Watt's bath (Ref. 18) at $60^{\circ} \mathrm{C}$ and $0.2 \mathrm{~A} / \mathrm{cm}^{2}$ for $5 \mathrm{~min}$. The specimen was placed in a cell, and the side with the $\mathrm{Ni}$ layer faced the anode cell. A three-electrode system was used in the anodic cells to measure the hydrogen permeation current. A saturated calomel electrode (SCE) was used as the reference electrode (RE), the Q355B specimen was used as the working electrode (WE), and a platinum plate was used as the counter electrode (CE). Before the experiment, the hydrogen detection side polarized at $300 \mathrm{mV}$ (vs. the SCE) for more than $24 \mathrm{~h}$ until the background current was less than $0.1 \mu \mathrm{A} \mathrm{cm}^{-2}$ in the $0.2 \mathrm{M}$ $\mathrm{NaOH}$ solution. To study the change of the hydrogen permeation current in the presence or absence of distilled water, hydrogen permeation tests were carried out in the presence and absence of 

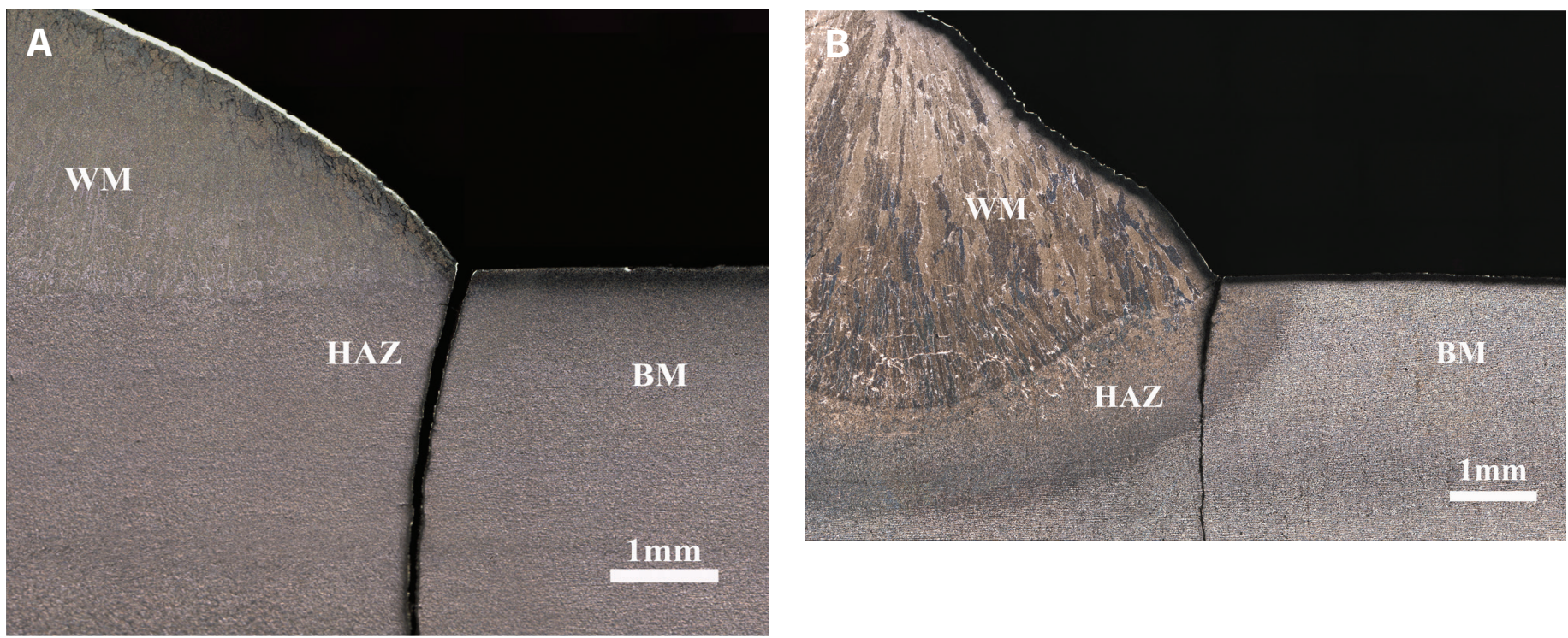

Fig'. 6 - Cross section of fatigue crack initiation sites for as-welded specimens: $A-\operatorname{In}$ dry air $\left(\Delta \sigma=100 \mathrm{MPa}, \mathrm{N}_{f}=\right.$ 2,899,379 cycles); $B-$ in the water-spray environment $\left(\Delta \sigma=90 \mathrm{MPa}, \mathrm{N}_{f}=2,150,638\right.$ cycles).

distilled water, respectively. When the hydrogen permeation test was conducted in the distilled water, nitrogen constantly flowed into the solution to exclude the oxygen in the air.

\section{Results}

\section{Experimental Results of As-Welded Joints}

\section{S-N Curve}

Figure 4 shows the $\mathrm{S}-\mathrm{N}$ curves for the as-welded specimens along with IIW's recommendations. The S-N curves were fitted according to IIW's recommendations (Ref. 19),

$$
C_{\mathrm{m}}=N(\Delta \sigma)^{m}
$$

where $C_{m}$ represents the constant in the S-N curve equation (50\% survival probability with $75 \%$ confidence level) with exponent $m$,
$N$ is the fatigue cycle, $\Delta \sigma$ is the nominal stress range, and $m$ is the slope of the S-N curve. As shown in Fig. 5, the heterogeneous population (Ref. 19) was actually present for welded joints tested in air and water-spray environments. However, due to the limited experimental fatigue data (see Fig. 5), the specific location of the knee point for welded joints tested in air could not be determined. Therefore, in light of IIW's recommendations, the fatigue life of $1 \times 10^{7}$ cycles was taken as the knee point. Although the S-N curve kept declining with the decrease in stress range for as-welded Table 3 - Fitting Results for the S-N Curves of
As-Welded Specimens

$\begin{array}{cccc}\text { Status } & \begin{array}{c}\text { Experimental } \\ \text { Environment }\end{array} & \boldsymbol{m} & \boldsymbol{C}_{\boldsymbol{m}}=\boldsymbol{N}(\Delta \sigma)^{\boldsymbol{m}} \\ & \text { In dry air } & 3.76 & 7.311 \times 10^{13}=N(\Delta \sigma)^{3.76} \\ \text { As-welded } & \text { Water spray } & 3.32 & 7.49 \times 10^{12}=N(\Delta \sigma)^{3.32}\end{array}$

Table 4 - Fatigue Strength of As-Welded Specimens at $50 \%$ Survival Probability

\section{Experimental \\ Environment}
Fatigue Strength
$\left(1 \times 10^{7}\right) \Delta \sigma$
(MPa)
Fatigue Strength
$\left(1 \times 10^{8}\right) \Delta \sigma$
(IMPa)

70

70

60.8
40 

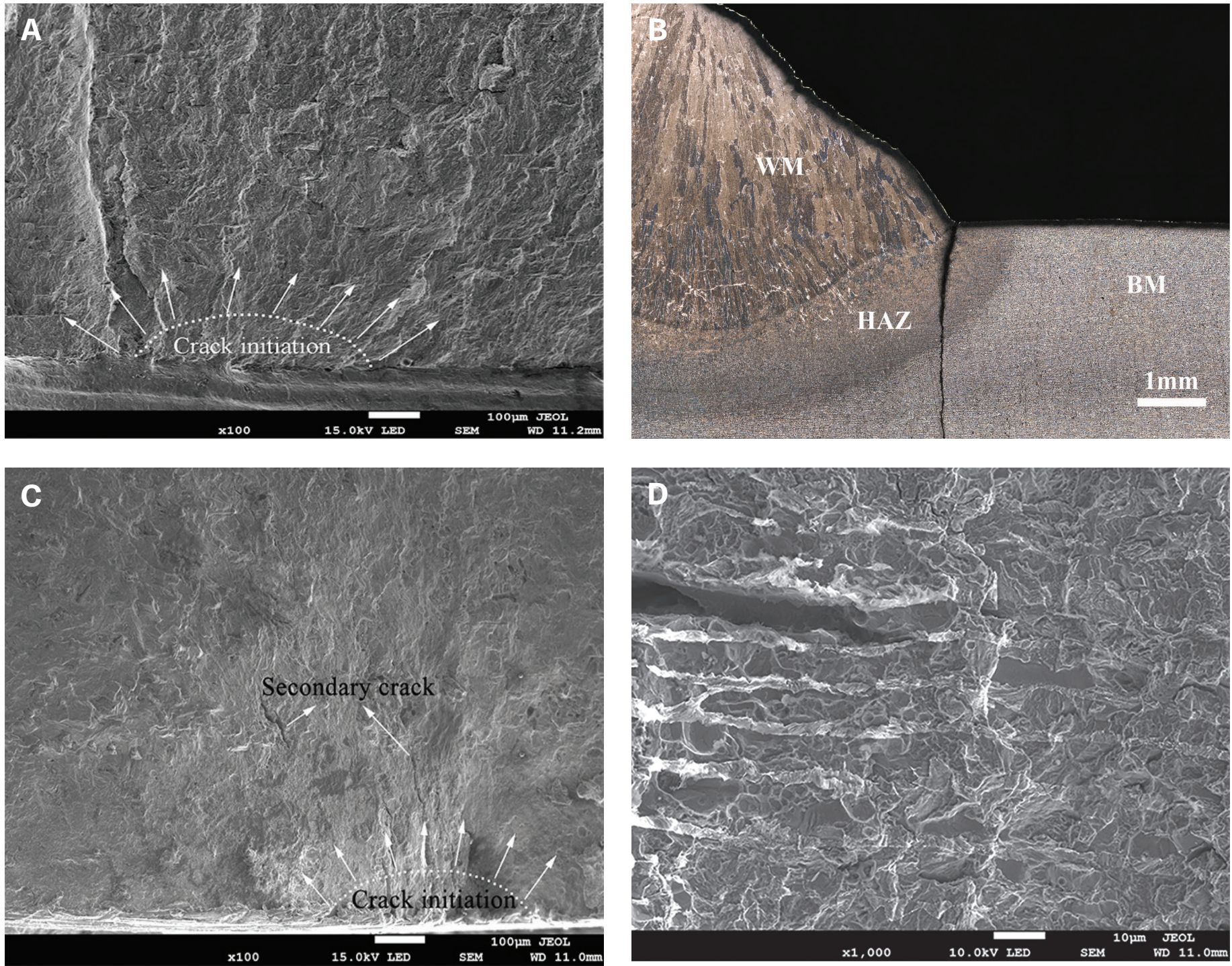

Fig. 7 - Specimen fracture morphology of as-welded specimens with various conditions: $A, B-$ In dry air $(\Delta \sigma=100 \mathrm{MPa}$, $\mathrm{N}_{f}=2,241,123$ cycles); $C, D-$ in the water-spray environment $\left(\Delta \sigma=50 \mathrm{MPa}, \mathrm{N}_{f}=14,967,437\right.$ cycles).

specimens in the water-spray environment with more than $1 \times 10^{7}$ cycles, the knee point also existed. It was located at about $N=5 \times 10^{7}$ cycles.

Table 3 presents the fitting results of the fatigue tests. The slopes of the S-N curves were 3.76 and 3.32 for the as-welded specimens in dry air and water-spray environments, respectively. These are bigger than $m=3$, which corresponds to the fatigue cycles below
$10^{7}$ recommended by IIW. According to the recommendations by IIW, for the steel as-welded fillet welds with a nonloadcarrying attachment, the fatigue class (FAT) was 80 . Therefore, it is important to notice that all fatigue data at a high applied stress range for as-welded specimens in the dry air environment and as-welded specimens in the water-spray environment were more than FAT 80. However, the curve for as-welded specimens

Table 5 - Geometric Parameters of Welded Joints Treated by HFMI

\begin{tabular}{ccccc}
\hline Status & $\begin{array}{c}\text { Weld Toe Radius } \\
(\mathbf{m m})\end{array}$ & $\begin{array}{c}\text { Groove Width } \\
(\mathbf{m m})\end{array}$ & $\begin{array}{c}\text { Groove Depth } \\
(\mathbf{m m})\end{array}$ & $\begin{array}{c}\text { Surface Roughness } \\
(\mu \mathbf{m})\end{array}$ \\
As-welded & 0.68 & - & - & 1.681 \\
HFMl treated & 1.55 & 3.06 & 0.37 & 3.319
\end{tabular}



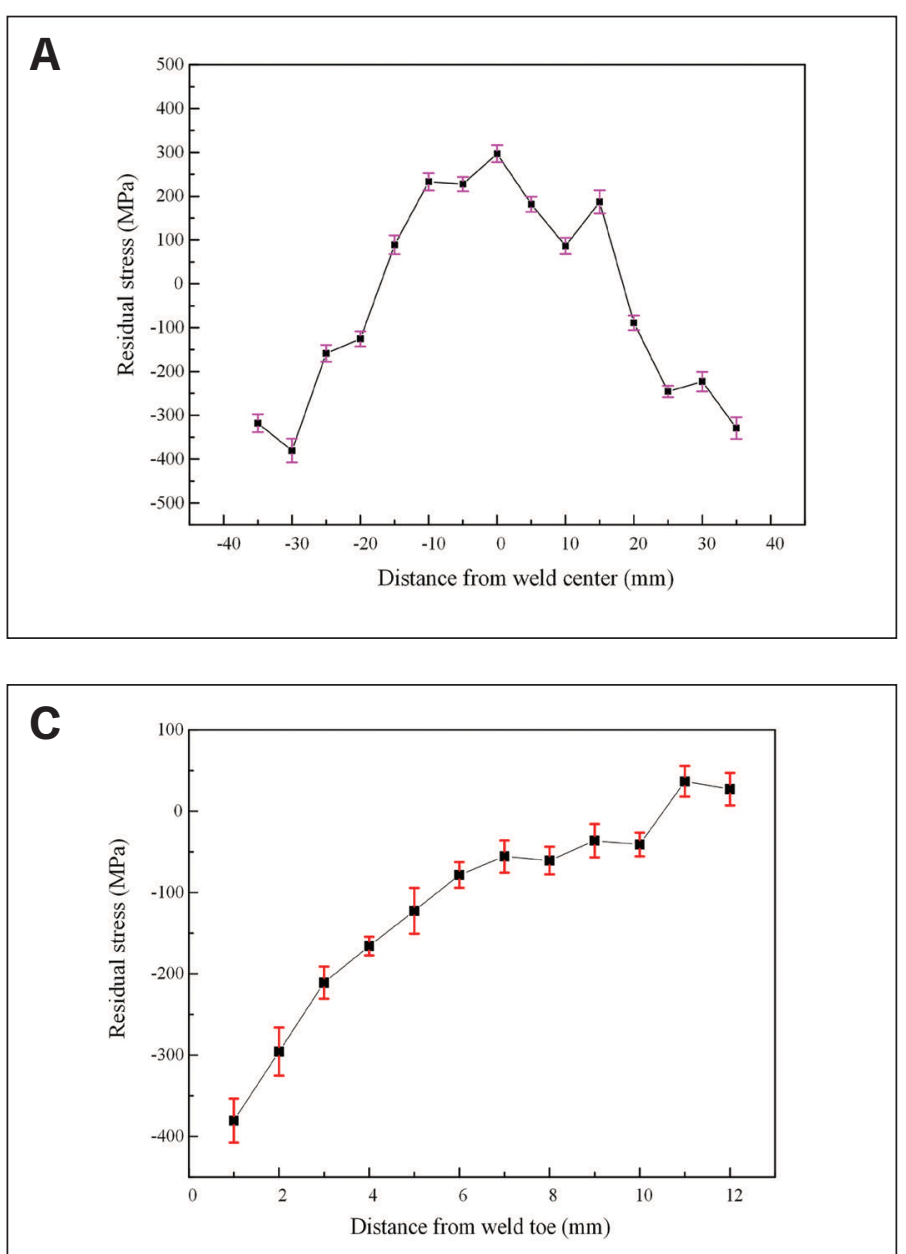

Fig. $8-A-$ Surface transverse residual stresses of the as-welded specimen along Path 1; $B$ - surface transverse residual stresses along' Path 2; C - surface transverse residual stresses along Path 3.

with $95 \%$ survival probability of the design line in the water-spray environment was less than FAT $80 \mathrm{~S}-\mathrm{N}$ curve. It was found that the design, as per IIW's recommendations, is conservative for fatigue life $N<1 \times 10^{7}$ in the dry air environment, while it is dangerous for welded joints in a water-spray environment. It is important to note that the fatigue strength of as-welded specimens in dry air corresponding to $N=1 \times 10^{7}$ and $N=2 \times 10^{8}$ were assumed to be $70 \mathrm{MPa}$ due to the existence of the traditional fatigue limit - Fig. 4. In contrast, the fatigue strength for as-welded specimens in the water-spray environment was designated as $40 \mathrm{MPa}$ because no fracture occurred between $10^{7}$ and $10^{8}$ cycles at this stress level.

Additionally, a comparison of the S-N curve from the test and the design S-N curves from British Standard (BS) 7608, Guide to fatigue design and assessment of steel products (Ref. 20), in the freely corroding seawater is also presented. All fatigue data for as-welded specimens in dry air were more than the BS $7608 \mathrm{E}$ curve in air, while some of the fatigue data in the water-spray VHCF regime were less than the BS 7608 E curve in air. The unexpected effect of the environment on the fatigue life of welded joints was obvious in the VHCF regime. Compared with the BS $7608 \mathrm{E}$ curve in the freely corroding seawater, all of the fatigue data in the dry

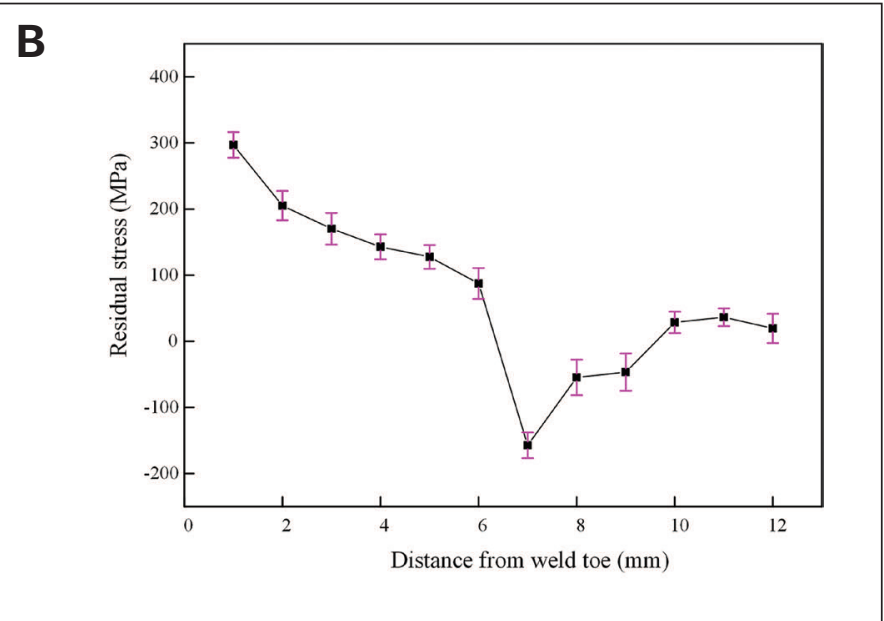

air and water-spray environments were also more than the BS $7608 \mathrm{E}$ curve in the freely corroding seawater. The difference in curves for as-welded specimens with $95 \%$ survival probability in the water-spray environment and the BS 7608 E curve in the freely corroding seawater was not significant when the fatigue life was $N<1 \times 10^{6}$ cycles. However, the curve for as-welded specimens with $95 \%$ survival probability in the water-spray environment was more than the BS 7608 E curve in the freely corroding seawater when the fatigue life regime was $N>1 \times 10^{6}$ cycles, which indicated that the BS $7608 \mathrm{E}$ curve is safe when corrosion factors are taken into account.

\section{Fractographic Observation of As-Welded Joints}

Figure 6 shows all of the fatigue cracks initiated from the weld toe. Figure 7 illustrates the fatigue fracture surface of as-welded specimens in dry air and water-spray environments. A river-like pattern appeared on the fracture surface of the specimen, and a striation-like character was also observed in the as-welded specimen in dry air with finer spacing - Fig. 7B. In addition, some secondary cracks were observed in the as-welded specimen in dry air. These cracks were perpendicular to the direction of crack growth, as shown in Fig. 7B, which might be due to the superimposition of external fatigue load and welding residual stress. However, in the water-spray environment, some secondary cracks were not only parallel to the direction of crack growth (see Fig. 7C) but also perpendicular to the direction of crack growth (see Fig. 7D). A significant difference was observed when the fatigue test was conducted under the water-spray environment. This was characterized by the appearance of a quasi-cleavage fracture and the disappearance of striations - Fig. 7D.

\section{Residual Stress of As-Welded Joints}

Figure 8 illustrates the distributions of transverse welding residual stresses for the as-welded specimen. The results show there was a high tensile residual stress at the center of the weld line, and the compressive residual stress was induced at both sides of the weld region for equilibrium - Fig. 8A. The maximum tensile residual stress near the center of the weld reached 296 $\mathrm{MPa}$, whereas the peak value of the compressive residual stress 

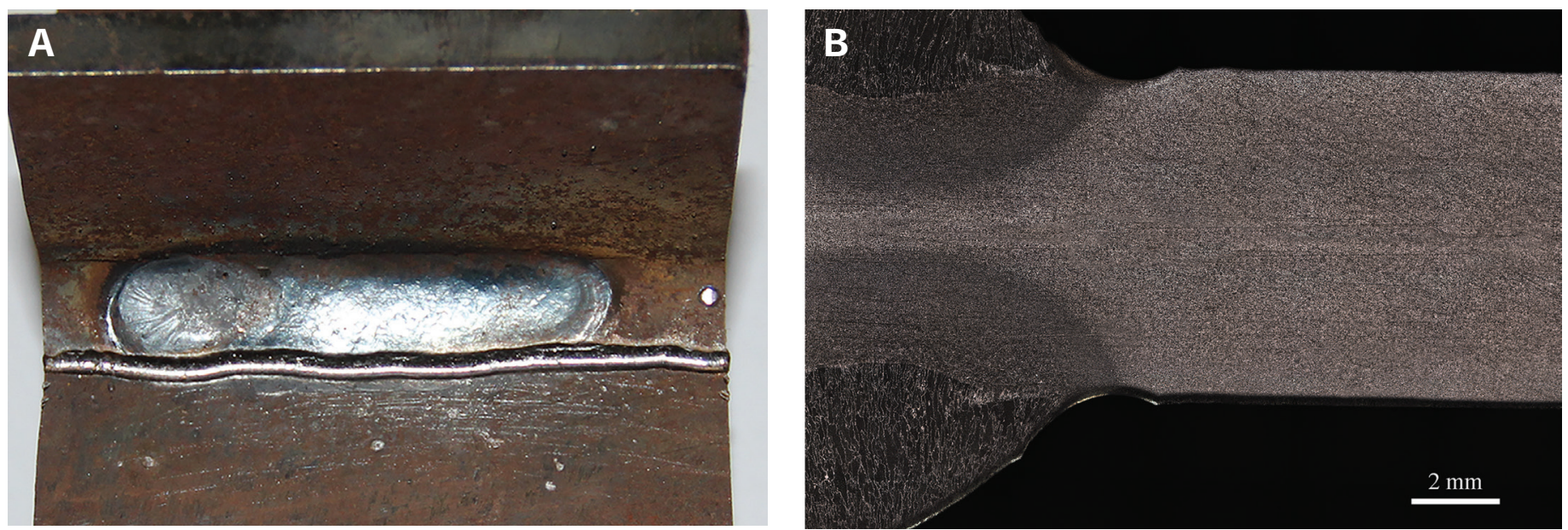

Fig. 9 - Weld toes after HFMI treatment: A - Macrograph of weld toe; B - cross-section profile.

around $380 \mathrm{MPa}$ appeared at a location that was $10 \mathrm{~mm}$ away from one side of the specimen.

The surface transverse residual stresses along Path 2 showed a downward trend as the distance from the weld toe increased (see Fig. 8B), and the residual stresses transformed into compressive stress when the distance was more than $7 \mathrm{~mm}$. In addition, Fig. $8 \mathrm{C}$ shows that the compressive residual stress at the specimen edge gradually decreased when the distance from the weld toe increased. The value of compressive residual stress was $380 \mathrm{MPa}$ at the weld toe. Compressive residual stresses were present in the area at about $8 \mathrm{~mm}$ from the weld toe.

\section{Experimental Results of HFMI-Treated Joints}

\section{Weld Geometry of HFMI-Treated Joints}

Figure 9 shows photos of the weld toe treated by HFMI. It can be seen that the groove was uniform, relatively smooth, and continuous with no breaks on the weld toe - Fig. 9A. The cross-section profile of the treated weld toe showed that local deformation caused by the HFMI treatment was located at the heat-affected zone. These parameters included groove width, weld toe radius, groove depth, and surface roughness (see Table 5). It could be seen that the weld toe radius after HFMI treatment increased compared to that of the as-welded joint. In addition, the surface roughness of the HFMI-treated welded joints increased slightly. After impact treatment, the depth and width of the groove were 0.37 and $3.06 \mathrm{~mm}$, respectively, which was consistent with IIW and BS 7608 (Refs. 14, 20).

\section{S-N Curves}

Figure 10 shows the S-N curves for HFMI-treated specimens under dry air and water-spray conditions. For HFMI-treated specimens, the conventional fatigue limit does not exist beyond $1 \times 10^{7}$ cycles regardless of whether they are in dry air or waterspray environments. Fatigue fracture still happened under low-stress range levels.
The fitting parameter results of fatigue tests and fatigue strength are listed in Tables 6 and 7, respectively. The slopes of S-N curves for HFMI-treated specimens were 6.04 in the water-spray environment and 17.7 in the dry air environment. According to IIW's recommendations (Ref. 14), the S-N curve slope for HFMI-treated welded joints is $m=5$ for $N<1 \times 10^{7}$ and $m=9$ for $N>1 \times 10^{7}$. Taking the environmental effect into account, the recommendation is only reasonable for $N<1 \times 10^{7}$ and nonconservative in the veryhigh-cycle regime $\left(N>1 \times 10^{7}\right)$.

For HFMI-treated specimens, no noticeable discrepancy was observed between the data of fatigue testing in air and waterspray environments at a higher stress range - Fig. 10. However, the difference became less trivial as the stress range decreased. The fatigue strength improved remarkably by HFMI treatment in a moist environment compared with the as-welded specimens. The improved behavior was attributed to compressive stresses as well as the stress-concentration smoothing induced by the HFMI treatment, which not only extended the stage of fatigue crack initiation but also promoted the microcrack closure and the corrosive media isolation. In comparison to the FAT 125 mentioned by IIW (Ref. 14) and BS 7608 (Ref. 20), the fatigue strength of HFMI-treated joints both in the dry air and water-spray environments were higher than the IIW standard and the BS 7608 design curve. They also had a much greater safety margin.

\section{Fractographic Observation of HFMI-Treated Joints}

The results of the fatigue tests showed that fatigue crack initiation sites were dependent on the load and environment. In the dry air environment, the fatigue initiation tended to locate at the weld toe (see Fig. 11A) and transfer to the weld root (see Fig. 11B) with the decrease in stress range. However, although the fatigue cracks in the water-spray environment initiated from the weld toe at a high stress range (see Fig. 11C), the initiation sites were still located at the base metal, as shown in Fig. 11D, at a low stress range.

The fatigue crack initiation sites and their distance from the weld toe of HFMI-treated specimens in different environments are presented in Fig. 12. It indicates that the sites of fatigue crack initiation were related to the stress range and test environment. 


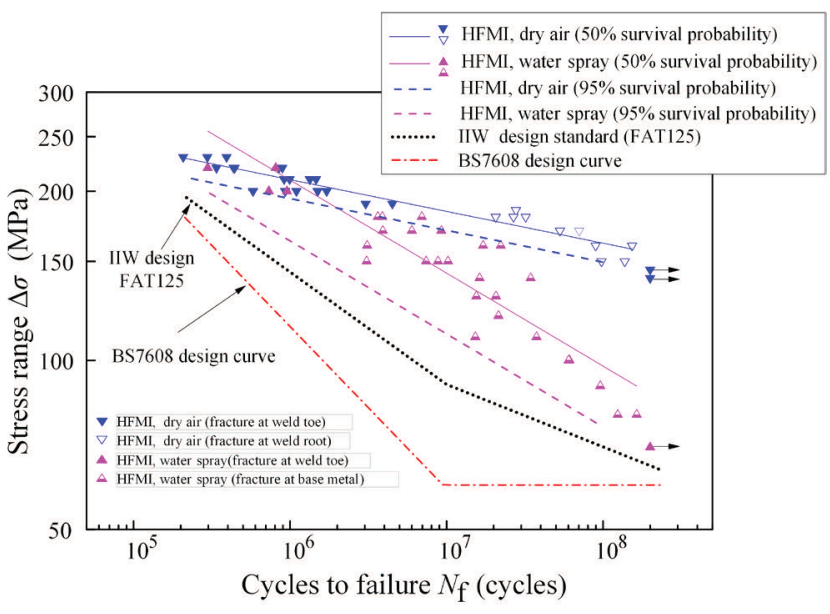

Fig'. $10-S-N$ curves of HFMI-treated specimens.

When the stress range was more than $185 \mathrm{MPa}$ in dry air, the weld toe was the fatigue crack initiation site. However, weld root cracking was dominated when the stress range was less than $185 \mathrm{MPa}$. When the test condition was in the water-spray environment, fatigue failure from the weld toe occurred when $\Delta \sigma>180 \mathrm{MPa}$, but the fatigue initiated from the base metal when $\Delta \sigma<180 \mathrm{MPa}$. Moreover, the crack initiation sites were mainly located at the base metal, where the distance was 4-9 $\mathrm{mm}$ from the weld toe. This mechanism will be discussed in more detail in the following section.

Figure 13 shows the fatigue fracture surface of HFMI-treated specimens in dry air. The macroscopic fatigue origin of the HFMItreated specimen at a high stress level was at the weld toe - Fig. 13A. Figure 13B uses arrows to indicate the tire tracks, which were induced by cyclic extrusion of the extended fatigue crack with two opposite surfaces due to the additional shear stresses caused by the compressive stress introduced by HFMI treatment (Ref. 21). Nevertheless, the fatigue crack initiation sites of the HFMI-treated specimen at a low stress level were at the weld root (see Fig. 13C, D), where the slag inclusion might have existed and promoted the fatigue crack initiation because of the presence of stress concentration. The EDS results demonstrate that chemical compositions of weld slag at the weld root were mainly comprised of $\mathrm{Ti}, \mathrm{Al}, \mathrm{Mg}$, Si, and O - Fig. 13E.

Fracture surface of the HFMI-treated specimen under the water-spray environment is shown in Fig. 14, where the cleavage-like morphology on the fracture surface can be seen even at a high stress range. Figure 14D shows an intergranular fracture with secondary cracks at a low stress level, which indicates the characteristic of grain boundary embrittlement as a result of the environmental effect. In addition, secondary cracks and an intergranular fracture on the fracture surface of specimens tested in the water-spray environment were observed, which could be evidence of a reduction in the grain boundary cohesive force based on the hydrogen-enhanced decohesion model in water-spray environments.

\section{Residual Stress of HFMI-Treated Specimens}

The distributions of surface transverse residual stresses in HFMI-treated specimens are presented in Fig. 15, where the compressive residual stresses along Path 1 with values of -184 to $-385 \mathrm{MPa}$ are also shown (Fig. 15A). Surface transverse residual stresses along Path 2 are shown in Fig. 15B. Compressive residual stress was introduced by severe plastic deformation of the surface layer, which altered the distribution of residual stress in the adjacent region of the weld toe. There existed compressive residual stress in the $\mathrm{HFMI}$-treated specimen in the region within $3 \mathrm{~mm}$ from the weld toe. Moreover, tensile residual stress was in the range of 4-9 $\mathrm{mm}$ from the weld toe, and the maximum tensile

Table 6 - Fitting Results for the S-N Curves of HFMI-Treated Specimens

\begin{tabular}{cccc} 
Status & $\begin{array}{c}\text { Experimental } \\
\text { Environment }\end{array}$ & $\boldsymbol{m}$ & $\mathbf{C}_{\mathbf{m}}=\boldsymbol{N}(\Delta \sigma)^{\mathbf{m}}$ \\
\hline HFMI treated & In dry air & 17.70 & $1.23 \times 10^{47}=N(\Delta \sigma)^{17.70}$ \\
& Water spray & 6.04 & $1.05 \times 10^{20}=N(\Delta \sigma)^{6.04}$
\end{tabular}

Table 7 - Fatigue Strength of Specimens at 50\% Survival Probability

\section{Experimental \\ Environment}

In dry air

Water spray

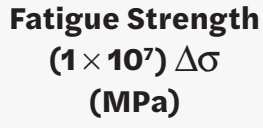

$\left(1 \times 10^{7}\right) \Delta \sigma$

(MPa)

184.0

142.9
Fatigue Strength

$\left(1 \times 10^{8}\right) \Delta \sigma$

(MPa)

161.5

97.6
12.2

Decrease (\%)

31.70 

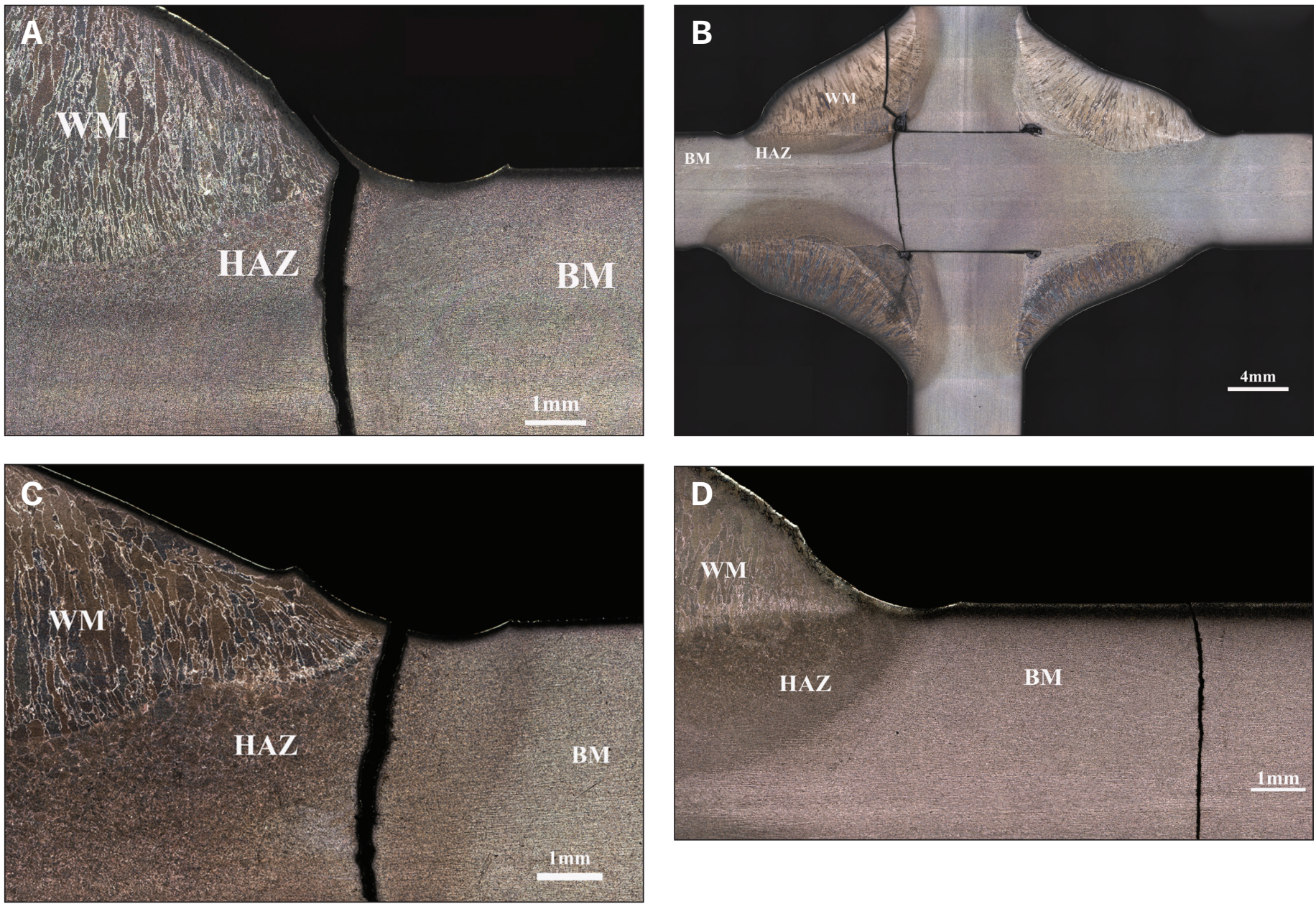

Fig. 11 - Cross sections of fatigue crack initiation sites for HFMI-treated specimens: $A-$ In dry air $\left(\Delta \sigma=200 \mathrm{MPa}, \mathrm{N}_{f}=\right.$ 931,208 cycles); $B-$ in dry air $\left(\Delta \sigma=180 \mathrm{MPa}, \mathrm{N}_{f}=32,057,426\right.$ cycles); $C$ - in the water-spray environment $(\Delta \sigma=200$ MPa, $\mathrm{N}_{f}=731,199$ cycles); $D-$ in the water-spray environment $\left(\Delta \sigma=130 \mathrm{MPa}, \mathrm{N}_{f}=20,688,932 \mathrm{cycles}\right)$.

residual stress of approximately $193 \mathrm{MPa}$ was located at an area of about $7 \mathrm{~mm}$ from the weld toe.

In addition, from Fig. 15C, it can be seen that the magnitude of compressive residual stress at the specimen edge decreased gradually for HFMI-treated specimens with the increased distance from the weld toe. Compressive residual stresses (value of -326 $\mathrm{MPa}$ ) existed at the weld toe for HFMI-treated specimens. The compressive residual stress was within $7 \mathrm{~mm}$ from the weld toe.

\section{Hydrogen Permeation Results}

Figure 16 shows the variation of the permeation current in distilled water. It was found that the hydrogen permeation current increased gradually with the extension of test duration due to corrosive action and reached a maximum value after about 250,000 s of testing. The result indicated that hydrogen can still be produced even in a distilled water environment. The reason for this decrease of the hydrogen permeation current in the distilled water was that the hydrogen in the steel itself was not yet completely diffused, and the hydrogen atoms that had generated on the cathode side had not diffused to the anode side. However, when the hydrogen atoms produced on the cathode side diffused to the anode side, the hydrogen permeation current increased gradually and then reached a peak. In this study, the steady hydrogen permeation current density was $0.253 \mu \mathrm{A} / \mathrm{cm}^{2}$. The apparent diffusion coefficient $\left(D_{\text {app }}\right)$ was calculated using Equation 2,

$$
D_{\mathrm{app}}=\frac{L^{2}}{6 \times t_{\mathrm{lag}}}
$$

where $t_{\text {lag }}$ is the time to achieve 0.63 of the steady-state permeation rate from the permeation curve, and $L$ is the specimen thickness $(0.005 \mathrm{~m})$. In this study, $t_{\text {lag }}$ was $135,000 \mathrm{~s}$.

The apparent subsurface concentration $C_{\text {oapp }}$ (ppmw) can be determined using the following expression (Ref. 22),

$$
C_{0 \text { app }}=\frac{\mathrm{I}_{\infty} L}{F D_{\text {app }}} \times \frac{M_{\mathrm{H}}}{\rho} \times 10^{6}
$$




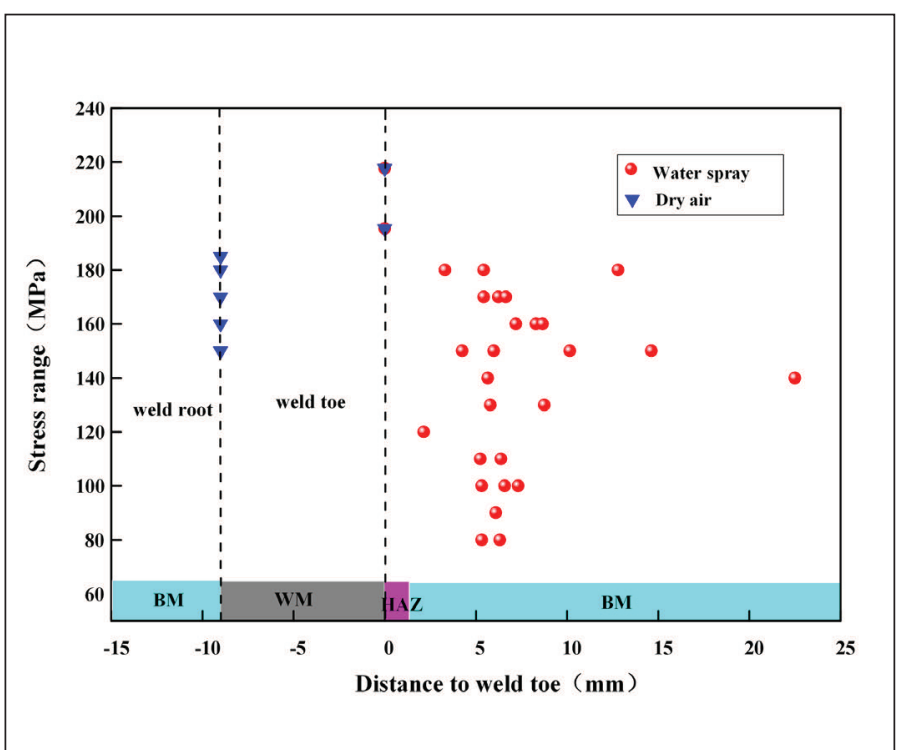

Fig. 12 - The relationship between fatigue crack initiation sites and the distance to the weld toe of HFMItreated specimens in different environments.

where 10 represents the steady-state permeation rate $\left(A / m^{2}\right)$, $F$ is the Faraday constant $(96,485 \mathrm{C} / \mathrm{mol}), M_{H}$ is the molar mass of hydrogen $(1 \mathrm{~g} / \mathrm{mol})$, and $\rho$ is the density of iron $\left(7.87 \times 10^{6} \mathrm{~g} /\right.$ $\mathrm{m}^{3}$ ). Therefore, it can be calculated that the hydrogen concentration of the subsurface was about 0.53 ppmw. Akiyama et al. (Ref. 23) proved that the low hydrogen concentration ( $<1 \mathrm{ppmw}$ ) still attributed to the hydrogen embrittlement of steel. When the hydrogen permeation test was conducted without distilled water, the hydrogen permeation current decreased and the fluctuation of the hydrogen permeation current was more severe, indicating that the test was more susceptible to external factors when there was no water film. The aforementioned detectable permeation current indicated that hydrogen evolution might play a role even in a distilled water environment.

\section{Discussion}

\section{The Effect of Hydrogen}

According to the hydrogen permeation test in the "Hydrogen Permeation Results" section of this paper, reduction of hydrogen ions still occurs even though the specimens are in distilled water - Fig. 16. The electrochemical reactions on the metal surface area in the distilled water environment were as follows: The anodic dissolution reaction was an oxidation reaction of iron (Ref. 24), as represented by Equation 4.

$$
\mathrm{Fe}-2 \mathrm{e} \rightarrow \mathrm{Fe}^{2+}
$$

The basic reduction reactions at the cathode are represented by Equations 5 and 6.

$$
\begin{gathered}
\mathrm{O}_{2}+2 \mathrm{H}_{2} \mathrm{O}+4 \mathrm{e} \rightarrow 4 \mathrm{OH}^{-} \\
\mathrm{H}^{+}+\mathrm{e} \rightarrow \mathrm{H}
\end{gathered}
$$

Huang et al. (Ref. 25) found that the value of $\mathrm{pH}$ deceased during the hydrogen permeation test with the increase of reaction time, which resulted in more $\mathrm{H}$ atom production. The adsorption of the $\mathrm{H}$ atom on the metal surface was the first step for $\mathrm{H}$ to enter into metal. The reactions of the electrochemical mechanism of hydrogen adsorption on the Fe sheet surface in double-distilled water are shown in Equations 7-9.

$$
\mathrm{H}_{2} \mathrm{O} \rightarrow \mathrm{H}^{+}+\mathrm{OH}^{-}
$$

$$
\begin{gathered}
\mathrm{H}_{3} \mathrm{O}^{+}+\mathrm{e} \rightarrow \mathrm{H}_{\mathrm{ad}}+\mathrm{H}_{2} \mathrm{O} \\
\mathrm{H}_{2} \mathrm{O}+\mathrm{e} \rightarrow \mathrm{H}_{\mathrm{ad}}+\mathrm{OH}^{-}
\end{gathered}
$$

In addition, the results showed that the $\mathrm{pH}$ value decreased at the metal-rust interface during the wet period. The hydrolysis reactions, which resulted in the decrease of $\mathrm{pH}$, are as follows (Ref. 25):

$$
\mathrm{Fe}^{2+}+\mathrm{H}_{2} \mathrm{O} \rightarrow \mathrm{FeOH}^{+}+\mathrm{H}^{+}
$$

$$
\mathrm{Fe}^{2+}+2 \mathrm{H}_{2} \mathrm{O} \rightarrow \mathrm{Fe}(\mathrm{OH})_{2}+2 \mathrm{H}^{+}
$$

$$
\begin{gathered}
3 \mathrm{Fe}^{2+}+4 \mathrm{H}_{2} \mathrm{O} \rightarrow \mathrm{Fe}_{3} \mathrm{O}_{4}+6 \mathrm{H}^{+}+2 \mathrm{H}_{\mathrm{ad}} \\
\mathrm{Fe}^{3+}+3 \mathrm{H}_{2} \mathrm{O} \rightarrow \mathrm{Fe}(\mathrm{OH})_{3}+3 \mathrm{H}^{+}
\end{gathered}
$$

The decrease of $\mathrm{pH}$ due to hydrolysis reactions could promote the reduction of hydrogen ions, which produced more hydrogen atoms, resulting in an increase in the hydrogen permeation current. The influence of hydrogen on fatigue strength of welded joints increased gradually with the increase in fatigue life, especially in the VHCF regime (Fig. 17). The effect of hydrogen was negligible 

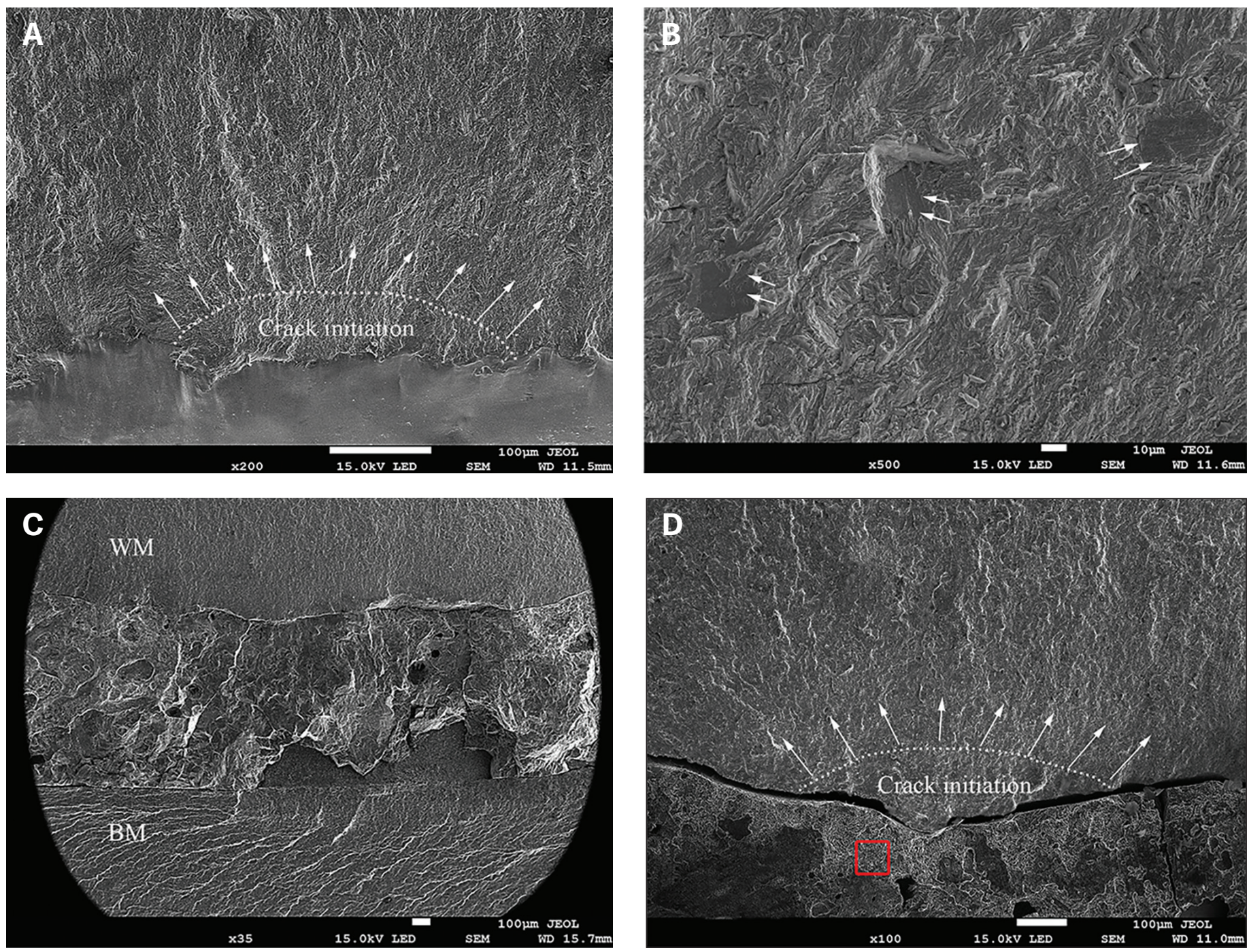

when the fatigue life was short due to the short action time of the reduction of hydrogen ions, and not much difference in the fatigue life was observed between the water-spray and air environments. However, with the stress range value decreased, the time for the reduction of hydrogen ions increased, which led to greater production of the hydrogen atoms, a significant effect of hydrogen.

In addition, the emergence of quasi-cleavage and cleavage features on the fracture surface was considered to be related to the effect of the hydrogen - Figs. 7, 14. Meanwhile, the fracture morphology showed the secondary crack and intergranular failure features, as presented in Fig. 14D, which might be related to trapped hydrogen atoms. This resulted in higher hydrogeninduced stress at the grain boundaries and a lower energy barrier (Refs. 26-28). Consequently, the microcracks may preferentially initiate phase boundaries.

\section{The Effect of Residual Stress Distribution}

Figure 18 shows the comparison of mean fatigue strength of welded joints with different cycles under various conditions. The fatigue strength improved substantially in the high-fatigue life and VHCF regime due to the HFMI treatment. As discussed previously,

$\mathbf{E}$

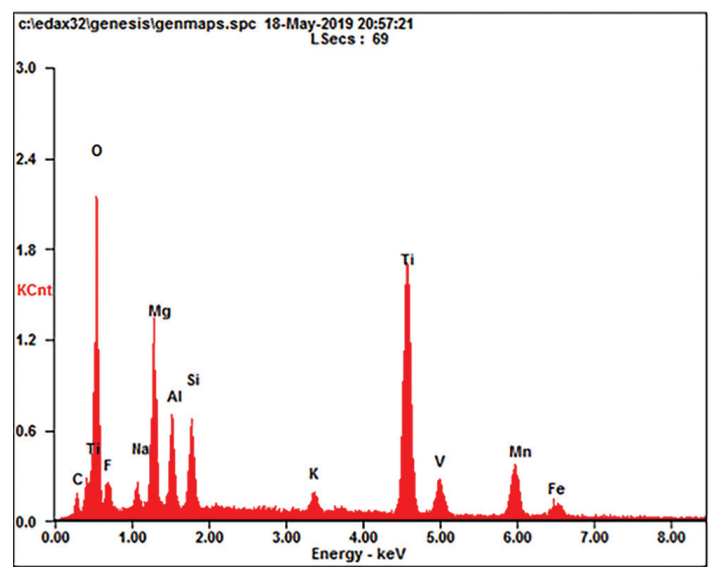

Fig. 13 - Fracture morphology of the HFMI-treated specimens in dry air: $A, B-\left(\Delta \sigma=220 \mathrm{MPa}, \mathrm{N}_{f}=891,181\right.$ cycles); $C, D-\left(\Delta \sigma=180 \mathrm{MPa}, \mathrm{N}_{f}=26,765,983\right.$ cycles $) ; E$ - EDS spectrum obtained from $D$. 

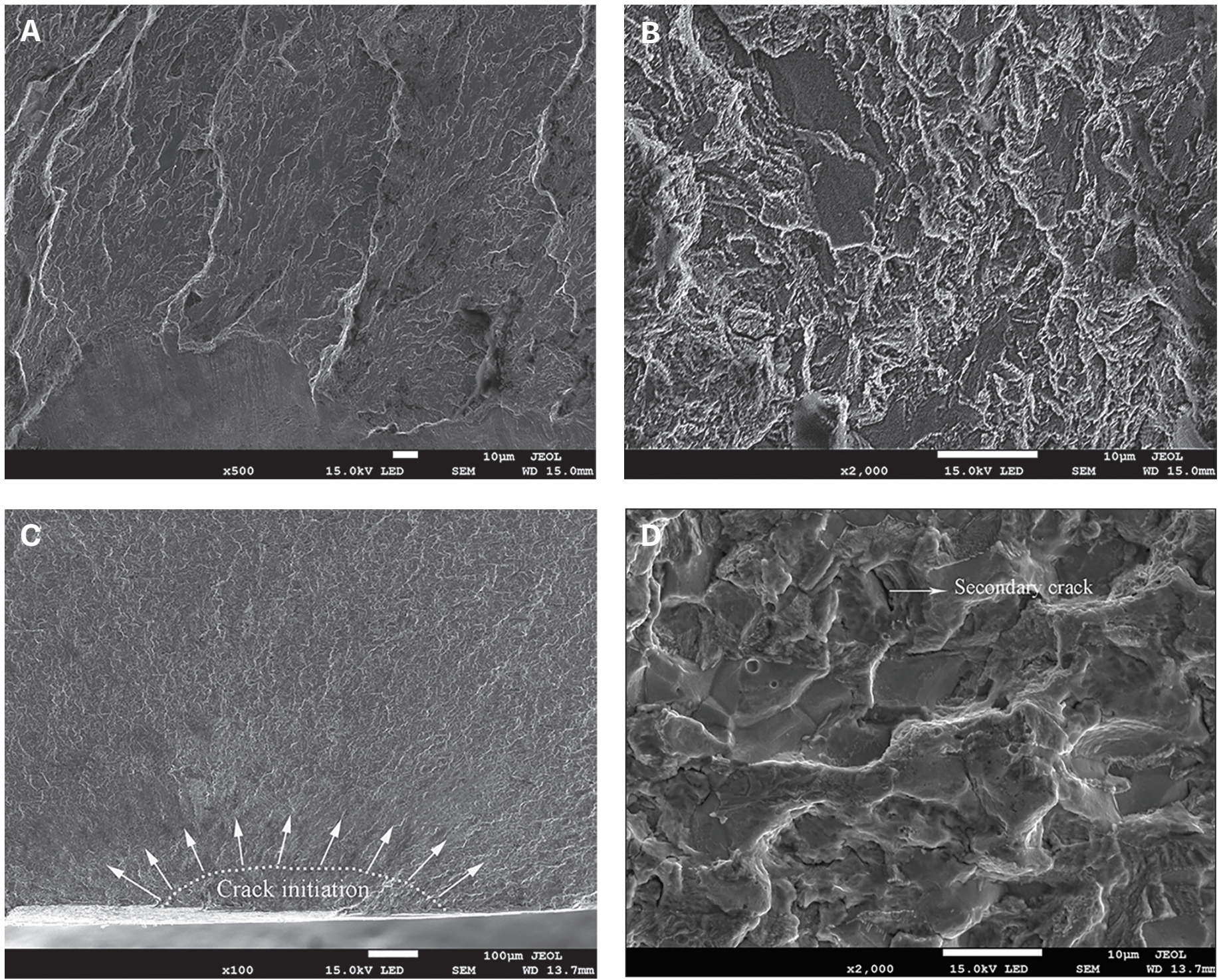

Fig'. 14 - Fracture morpholog'y of HFMI-treated specimens in the water-spray environment: $A, B-\left(\Delta \sigma=220 \mathrm{MPa}, \mathrm{N}_{f}=\right.$ $297,400$ cycles $) ; C, D-\left(\Delta \sigma=80 \mathrm{MPa}, \mathrm{N}_{f}=124,061,197\right.$ cycles $)$.

the redistribution of residual stress may have a significant effect on the improvement of fatigue life.

The local stress ratio in the area adjacent to the weld toe was different from the nominal stress ratio because the residual stress field was superimposed on the constant stress ratio (Ref. 29). The local stress ratio increased due to the presence of tensile residual stress, which led to the acceleration of the fatigue crack growth rate. Hence, fatigue cracks initiation sites were prone to be at the weld toe for as-welded specimens. For HFMI-treated specimens, the external applied stress was partially offset by the compressive residual stress generated by the HFMI treatment. The fatigue enhancement by the HFMI treatment was not significant at a higher stress range owing to the plastic relaxation of beneficial compressive residual stress (Refs. 30, 31). In this case, the fatigue failure mode was expected at the weld toe. As the applied stress range decreased, the compressive residual stress was not easy to relax and could be maintained to a large extent. Therefore, the initiation of the fatigue crack was inhibited, and the propagation stage was obviously blocked. As a result, the fatigue performance at the weld toe was significantly improved. Under the combined action of high-stress concentration at the weld root and tensile residual stress, fatigue failure was transferred from the weld toe to the weld root. Additionally, even though the fatigue crack initiation sites changed with the decrease of the applied stress range, the slope of the HFMI-treated S-N curve was flatter than that of the as-welded specimen. It was indicated that the fatigue crack propagation rate for HFMI-treated specimens initiating from the weld root was slower than that of the as-welded specimens initiating from the weld toe. 

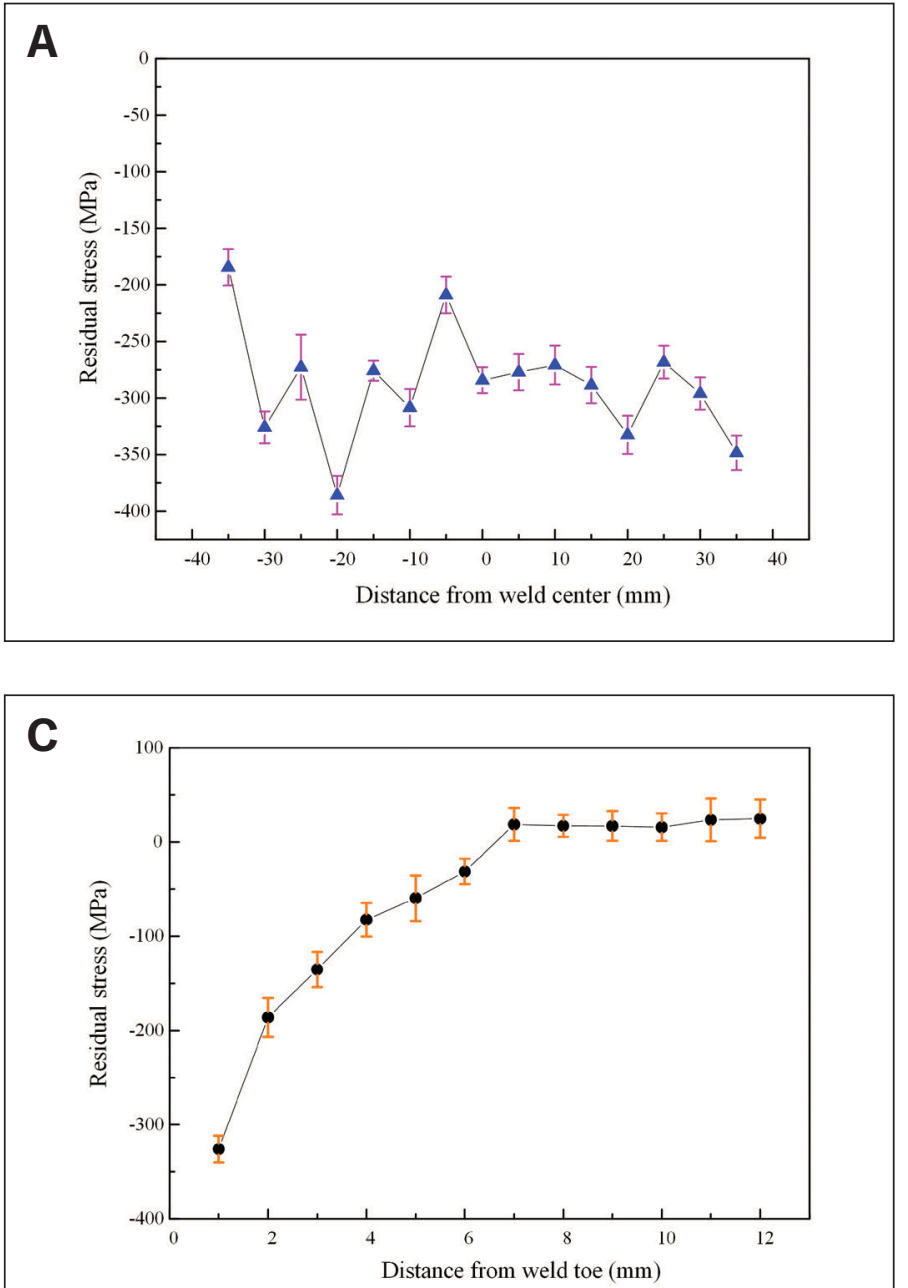

Fig.15 - A- Surface transverse residual stresses of HFMI-treated specimens along Path 1; B - surface transverse residual stresses along Path 2; $C$ - surface transverse residual stresses along Path 3.

\section{The Synergetic Effect of Hydrogen and Distribution of Residual Stress}

In practice, the sea-crossing steel bridges with a frequency of about $1 \mathrm{~Hz}$ (Ref. 32) are subjected to fatigue load in the VHCF regime (around $10^{9}$ cycles), which is consistent with the life range of fatigue tests. Although welded joints are protected by coatings, the service life of coatings is only about ten years. Once the coating is deboned locally, the synergetic effect of the corrosive environment and fatigue load would exceed the welding component failure. During the in-service phase of a bridge, maintenance and repair personnel are extremely important.

This study not only demonstrated the fatigue behavior of welded joints under a relatively weak corrosive environment but also provided experimental evidence for the structural integrity assessment and maintenance period. From the fatigue results, it could be proven that the environmental factor significantly affects the fatigue life of welded joints. The interactions between
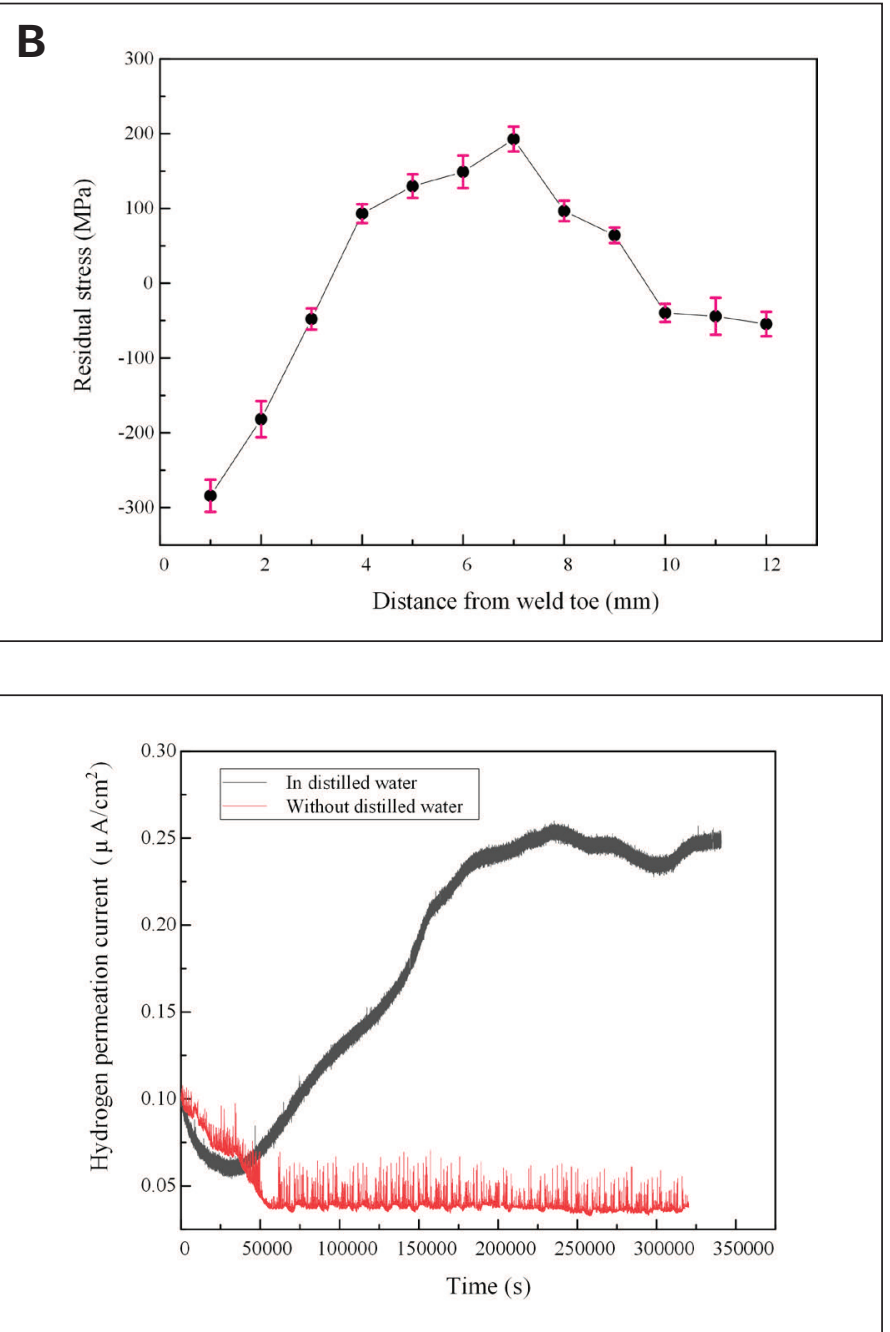

Fig. 16 - Change in the hydrogen permeation current under various conditions.

hydrogen atoms and residual stress of as-welded specimens are shown in Fig. 19.

For welded joints, the crack nucleation stage can be negligible as a result of the presence of defects in the weld in comparison with the crack propagation stage. Thus, the fatigue life was controlled by the crack propagation stage and associated with the crack propagation rate. That the change in the local stress ratio in the area adjacent to the weld toe, as well as the reduction of the intensity factor threshold owing to the effect of corrosion, would increase the crack propagation rate of the welded joints in the water-spray environment indicated a decrease in fatigue life. In addition, the weld toe was a negative potential site because the stress potential was directly proportional to the stress level (Ref. 33).

Meanwhile, the hydrogen atom absorption and the adsorption under cyclic stress caused the local activation of the metal surfaces, allowing cracks to initiate more easily from the weld toe. As hydrogen ions diffused into the crack tip, the decrease in $\mathrm{pH}$ near the crack tip promoted the reduction of hydrogen ions and led to the production of more hydrogen atoms, which may 
A

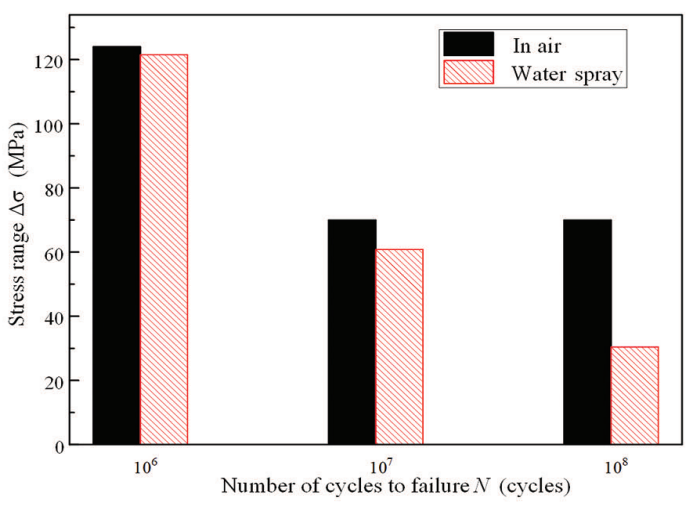

B

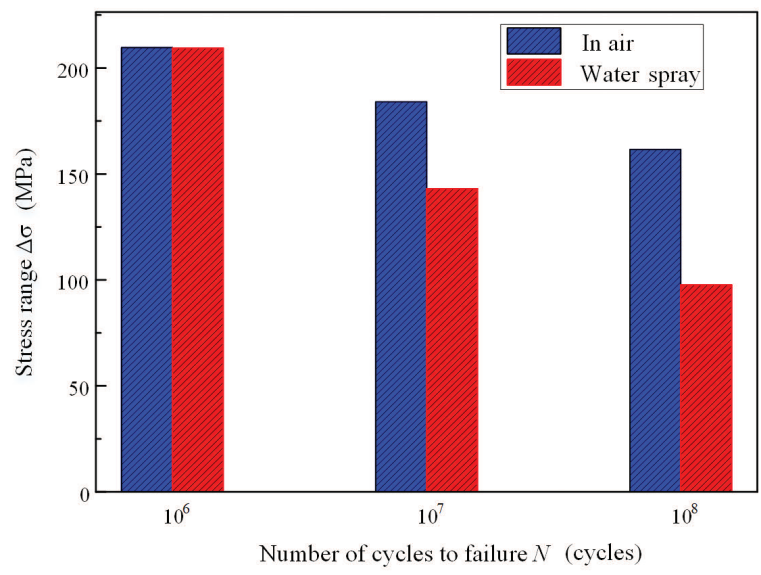

Fig'. 17 - The mean fatigue strength with various cycles: A - As-welded; B - HFMI treated.

A

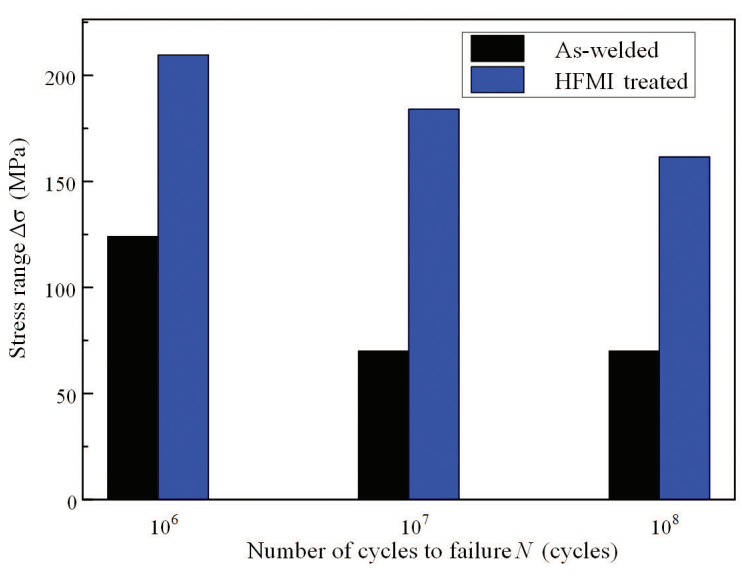

B

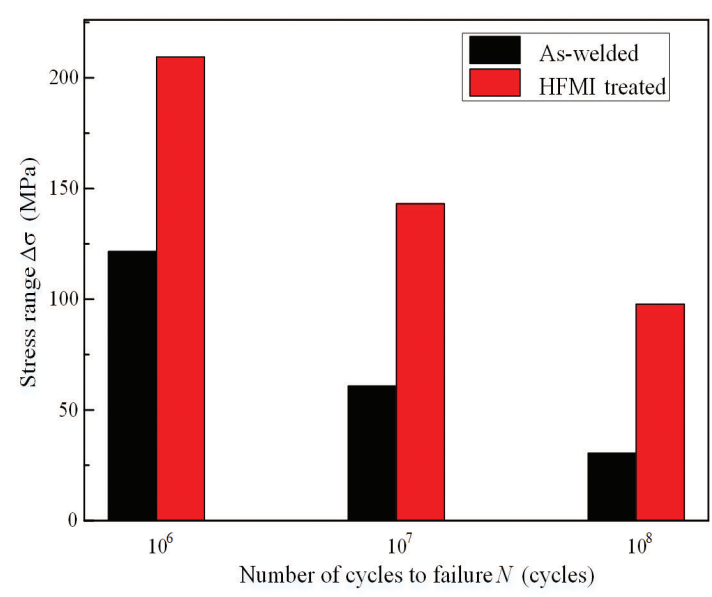

Fig. 18 - The comparison of mean fatigue strength of welded joints with various cycles under different conditions: A In air; $B-$ water spray.

cause local hydrogen embrittlement. Finally, under the synergetic effect of tensile residual stress, externally applied cyclic stress, and stress concentration, fatigue cracks still initiated from the weld toe even at a lower stress level.

Fatigue crack initiation sites are seemingly dependent on residual stress distribution for HFMI-treated specimens - Fig. 20. When the stress range exceeded a certain value, the weld toe became the site for fatigue crack initiation due to the short action time of corrosion. As the stress range decreased, the corrosion effect became much more significant and most of the fatigue cracks initiated at the base metal, where the distance was within 4-9 $\mathrm{mm}$ from the weld toe at the middle of the specimen with the high tensile residual stresses. In addition, crack initiation sites were not at the edge of the specimens because compressive residual stress existed at the sites 4-9 $\mathrm{mm}$ away from the weld toe (Fig. 15). The interactions between the tensile residual stress and the environment for HFMI-treated welded joints at a low stress range are illustrated in Fig. 21.
Under a low stress level, compressive residual stress and grain refinement at the weld toe surface layer produced by HFMItreated hindered both fatigue crack nucleation and growth and also improved corrosion resistance by inhibiting the production of hydrogen atoms. However, the superposition of high-tensile residual stress at $4-9 \mathrm{~mm}$ from the weld toe and external tensile stress increased the corrosion rate and promoted the hydrogen ion reduction to produce more hydrogen atoms. Additionally, the presence of tensile residual stress increased the stress ratio, and the corrosive environment reduced the intensity factor threshold. Both of these accelerate the fatigue crack propagation rate. Thus, fatigue crack was more prone to initiate from the base metal at locations 4-9 $\mathrm{mm}$ away from the weld toe at a low stress level.

\section{Conclusions}

This work investigated the fatigue behavior of welded joints in terms of environment (air and water) and weld toe treatment (as-welded and HFMI treated). The conclusions are as follows: 

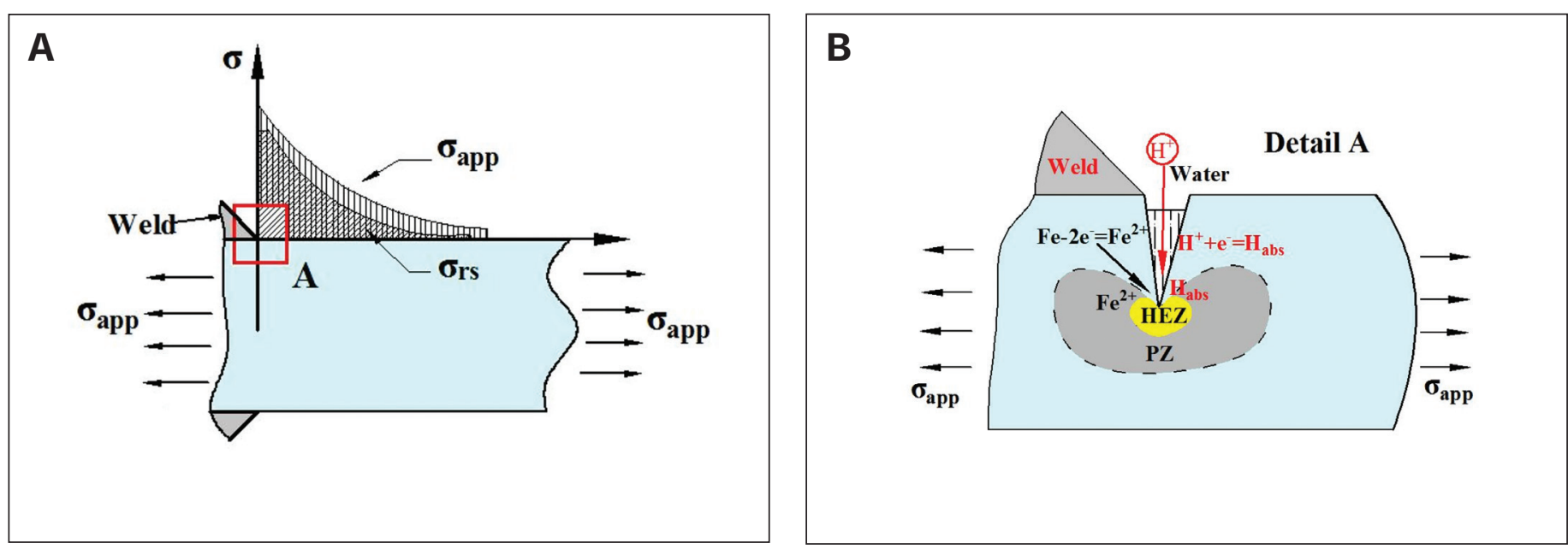

Fig. 19 - Sketches of the coupling effect of stress distribution and hydrogen on fatigue crack propagation for as-welded cruciform joints in the water-spray environment: A-Distribution of applied $\left(\sigma_{\text {app }}\right)$ and residual $\left(\sigma_{r s}\right)$ stresses at the weld toe; $B$ - magnification of the weld toe sketched with square A in A. (Note: HEZ - hydrogen embrittlement zone; PZ plastic zone.)

1) For as-welded specimens, the slopes of the $S-N$ curves with a $50 \%$ survival probability with a confidence of $75 \%$ were 3.76 and 3.32 in dry air and water-spray environments. The fatigue strengths of the as-welded specimens in dry air and water-spray environments were 70 and $40 \mathrm{MPa}$ at $N=2 \times 10^{8}$, respectively. In contrast, the slopes of HFMI-treated S- $\mathrm{N}$ curves with $50 \%$ survival probability and with a confidence of $75 \%$ were 17.70 and 6.04 in dry air and water-spray environments, respectively. The fatigue strengths of the HFMI-treated specimens in dry air were 184.0 MPa for $N=1 \times 10^{7}$ and $161.5 \mathrm{MPa}$ for $N=1 \times 10^{8}$. The fatigue strengths of the HFMI-treated specimens in the water-spray environment were 142.9 $\mathrm{MPa}$ for $N=1 \times 10^{7}$ and $97.6 \mathrm{MPa}$ for $N=1 \times 10^{8}$. This indicated that the difference in fatigue life with the decreased stress range became pronounced under two conditions.

2) The hydrogen permeation result indicated that hydrogen can still be produced even in a distilled water environment, while the hydrogen permeation current continuously decreased and fluctuated greatly in the absence of distilled water. The above detectable permeation current indicated that, although the hydrogen atom activity was weak, the role of hydrogen evolution may deserve further study.

3) The fatigue crack initiated at the weld toe for the as-welded and HFMI-treated specimens under two test environments. As the stress range decreased, the fatigue failure transferred from the weld toe to the weld root and base metal in the dry air and water-spray environments for HFMI-treated joints. The fatigue crack initiation transition from the weld toe to the weld root was attributed to the high compressive residual stress at the weld toe as well as the stress concentration caused by slag inclusion at the weld root. The fatigue crack initiation sites transferred from the weld toe to the base metal owing to the synergetic effect of the corrosion factors and tensile residual stress at the base metal within 4-9 $\mathrm{mm}$ away from the weld toe.

\section{Acknowledgments}

The research was financially supported by the National Natural Science Foundation of China (Grant No. 51875402).

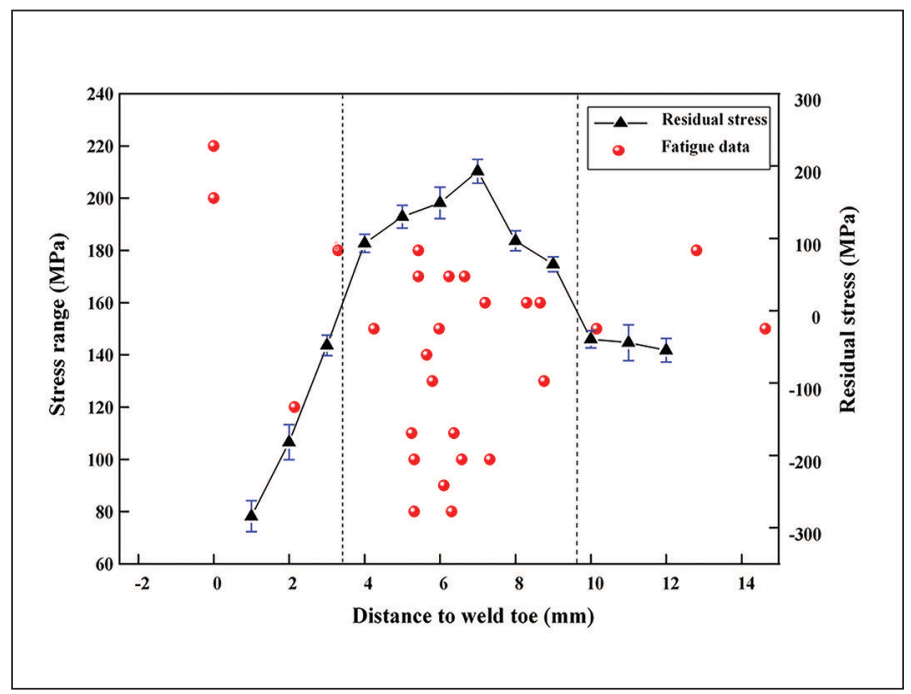

Fig. 20 - Fatigue data of HFMI-treated specimens vs. residual stress in the water-spray environment.

\section{References}

1. Teng, T. L., Fung, C. P., and Chang, P. H. 2002. Effect of weld geometry and residual stresses on fatigue in butt-welded joints. International Journal of Pressure Vessels \& Piping 79(7): 467-482. DOI: 10.1016/S0308-0161(02)00060-1

2. Ngoula, D. T., Beier, H. T., and Vormwald, M. 2017. Fatigue crack growth in cruciform welded joints: Influence of residual stresses and of the weld toe geometry. International Journal of Fatigue 101(2): 253-262. DOI: 10.1016/j. ijfatigue.2016.09.020

3. Deschênes, P. A., Lanteigne, J., Verreman, Y., Paquet, D., Lévesque, J. B., and Brochu, M. 2017. A new experimental method to study the influence of welding residual stresses on fatigue crack propagation. International Journal of Fatigue 100: 444-452. DOI: 10.1016/j.ijfatigue.2017.01.031

4. Do, V. N. V., Lee, C. H., and Chang, K. H. 2015. High cycle fatigue analysis in presence of residual stresses by using a continuum damage mechanics model. International Journal of Fatigue 70(1): 51-62. DOI: 10.1016/j.ijfatigue.2014.08.013

5. Hensel, J., Nitschke-Pagel, T., and Dilger, K. 2016. Effects of residual stresses and compressive mean stresses on the fatigue strength of longitudinal fillet-welded gussets. Welding in the World 60(2): 267-281. DOI: 10.1007/s40194-015-0284-6 

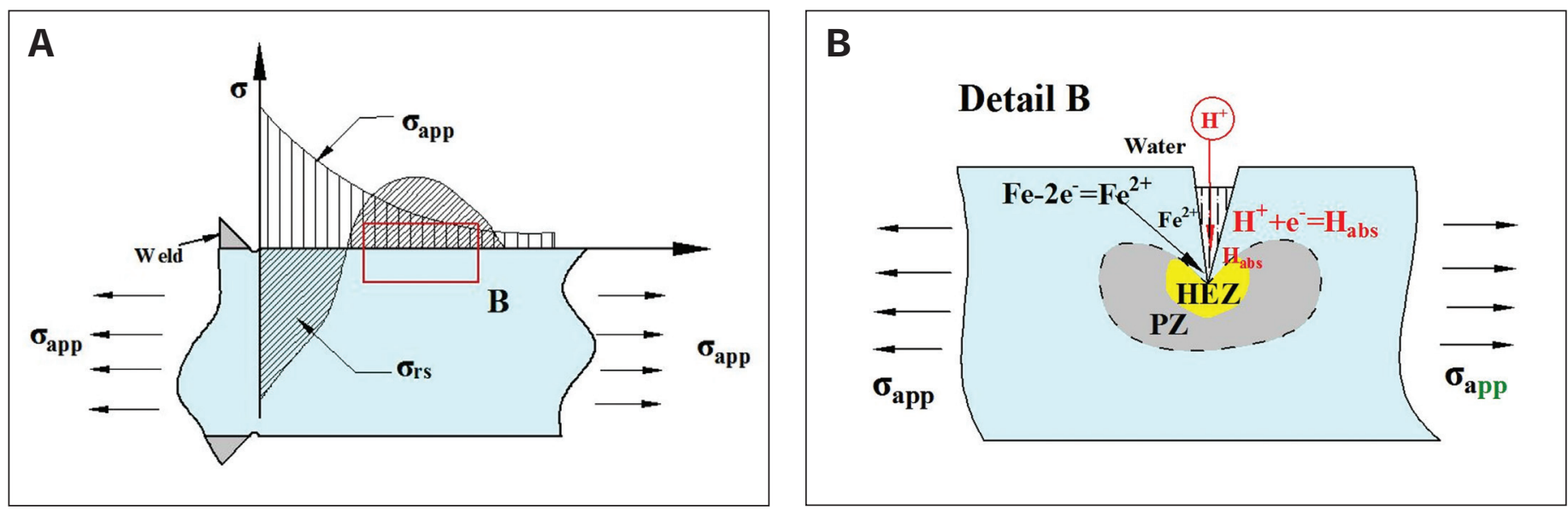

Fig. 21 - Sketches of the coupling effect of stress distribution and hydrogen on fatigue crack propagation for HFMItreated cruciform joints in the water-spray environment: $A-$ Distribution of applied $\left(\sigma_{\text {app }}\right)$ and residual $\left(\sigma_{r s}\right)$ stresses at the weld toe; $B-$ magnification of the weld toe sketched with square $A$ in $A$. (Note: HEZ - hydrogen embrittlement zone; PZ - plastic zone).

6. Qian, G., Zhou, C., and Hong, Y. 2011. Experimental and theoretical investigation of environmental media on very-high-cycle fatigue behavior for a structural steel. Acta Materialia 59(4): 1321-1327. DOI: 10.1016/j.actamat.2010.10.064

7. Genel, K., Demirkol, M., and Gülmez, T. 2000. Corrosion fatigue behaviour of ion nitrided AISI 4140 steel. Materials Science \& Engineering A 288(1): 91-100 DOI: 10.1016/S0921-5093(00)00835-2

8. Baptista, R., Infante, V., and Branco, C. M. 2008. Study of the fatigue behavior in welded joints of stainless steels treated by weld toe grinding and subjected to salt water corrosion. International Journal of Fatigue 30(3): 453-462. DOI: 10.1016/j.ijfatigue.2007.04.011

9. Tokaji, K., Ko, H. N., Nakajima, M., and Itoga, H. 2003. Effects of humidity on crack initiation mechanism and associated $\mathrm{S}-\mathrm{N}$ characteristics in very high strength steels. Materials Science \& Engineering A 345(1-2): 197-206. DOI: 10.1016/ S0921-5093(02)00460-4

10. Ilman, M. N., Triwibowo, N. A., Wahyudianto, A., and Muslih, M. R. 2017. Environmentally assisted fatigue behaviour of stress relieved metal inert gas (MIG) AA5083 welds in 3.5\% NaCl solution. International Journal of Fatigue 100: 285-295. DOI: 10.1016/j.ijfatigue.2017.03.041

11. Hudak, S. J. J., Burnside, O. H., and Chan, K. S. 1984. Analysis of corrosion fatigue crack growth in welded tubular Joints. Journal of Energy Resources Tech nology 107(2): 212-219. DOI: 10.1115/1.3231179

12. Chung, S. H., Lim, J. K., and Na, E. G. 1989. Environmental strength evaluation of welded steel joint in seawater. KSME International Journal 3:1-5. DOI 10.1007/bf02945676

13. Knysh, V. V., Solovei, S. A., Kadyshev, A. A Nyrkova, L. I., and Osadchuk, S. A. 2017. Influence of high-frequency peening on the corrosion fatigue of welded joints. Materials Science 53(1): 1-7. DOI: 10.1007/s11003-017-0036-4

14. Marquis, G. B., and Barsoum, Z. 2016. IIW Recommendations for the HFM Treatment: For Improving the Fatigue Strength of Welded Joints. Singapore: Springer, pp.1-34.

15. Roy, S., Fisher, J. W., and Yen, B. T. 2003. Fatigue resistance of welded details enhanced by ultrasonic impact treatment (UIT). International Journal of Fatigue 25(9-11): 1239-1247. DOI: 10.1016/S0142-1123(03)00151-8

16. Yildirim, H. C., and Marquis, G. B. 2012. Fatigue strength improvement factors for high strength steel welded joints treated by high frequency mechanical impact. International Journal of Fatigue 44:168-176. DOI:10.1016/j.ijfatigue.2012.05.002

17. Okawa, T., Shimanuki, H., Funatsu, Y., Nose, T., and Sumi, Y. 2013. Effect of preload and stress ratio on fatigue strength of welded joints improved by ultrasonic impact treatment. Welding in the World 57(2): 235-241. DOI: 10.1007/s40194012-0018-y

18. Tian, H., Wang, X., Cui, Z., Lu, Q., Wang, L., Lei, L., Li, Y., and Zhang, D. 2018 Electrochemical corrosion, hydrogen permeation and stress corrosion cracking behavior of E690 steel in thiosulfate-containing artificial seawater. Corrosion Science 144: 145-162. DOI: 10.1016/j.corsci.2018.08.048

19. Hobbacher, A. F. 2016. Recommendations for fatigue design of welded joints and components. IIW Doc. XIII-2460-13.

20. British Standards Institution. BS 7608:2014, Guide to Fatigue Design and Assessment of Steel Products. BSI: London, UK.
21. Zhang, H., Wang, D., Xia, L., Lei, Z., and Li, Y. 2015. Effects of ultrasonic impact treatment on pre-fatigue loaded high-strength steel welded joints. International Journal of Fatigue 80: 278-287. DOI: 10.1016/j.ijfatigue.2015.06.017

22. Frappart, S., Feaugas, X., Creus, J., Thebault, F., Delattre, L. and Marchebois, H. 2012. Hydrogen solubility, diffusivity and trapping in a tempered $\mathrm{Fe}-\mathrm{C}-\mathrm{Cr}$ martensitic steel under various mechanical stress states. Materials Science and Engineering A 534: 384-393. DOI: 10.1016/j.msea.2011.11.084

23. Akiyama, E., Wang, M., Li, S., Zhang, Z., and Kimura, Y. 2013. Studies of evaluation of hydrogen embrittlement property of high-strength steels with consideration of the effect of atmospheric corrosion. Metallurgical \& Materials Transactions $A$ 44(3): 1290-300. DOI: 10.1007/s11661-012-1403-2

24. Evans, U. R. 1965. Electrochemical mechanism of atmospheric rusting. Nature 206: 980-982

25. Huang, Y., and Zhu, Y. 2005. Hydrogen ion reduction in the process of iron rusting. Corrosion Science 47(6): 1545-1554. DOI: 10.1016/j.corsci.2004.07.044

26. Martin, M. L., Dadfarnia, M., Nagao, A., Wang, S., and Sofronis, P. 2019. Enumeration of the hydrogen-enhanced localized plasticity mechanism for hydrogen embrittlement in structural materials. Acta Materialia 165: 734-750. DOI:10.1016/j. actamat.2018.12.014

27. Zhang, T., Chu, W. Y., Gao, K. W., and Qiao, L. J. 2003. Study of correlation between hydrogen-induced stress and hydrogen embrittlement. Materials Science \& Engineering A 347(1): 291-299. DOI: 10.1016/S0921-5093(02)00600-7

28. Kirchheim, R. 2007. Reducing grain boundary, dislocation line and vacancy formation energies by solute segregation: II. Experimental evidence and consequences. Acta Materialia 55(15): 5139-5148. DOI: 10.1016/j.actamat.2007.05.033

29. Wang, D., Zhang, H., Gong, B., and Deng, C. 2016. Residual stress effects on fatigue behaviour of welded T-joint: A finite fracture mechanics approach. Materials \& Design 91: 211-217. DOI: 10.1016/j.matdes.2015.11.106

30. Pedersen, M. M. M., Mouritsen, O. Ø., Hansen, M. R., Andersen, J. G., and Wenderby, J. 2010. Comparison of post-weld treatment of high-strength steel welded joints in medium cycle fatigue. Welding in the World 54(7-8): 208-217.

31. Zhuang, W. Z., and Halford, G. R. 2001. Investigation of residual stress relaxation under cyclic load. International Journal of Fatigue 23(1): 31-37. DOI: 10.1016/ S0142-1123(01)00132-3

32. Maljaars J. Evaluation of traffic load models for fatigue verification of European road bridges[J]. Engineering Structures 225: 111326. DOI: 10.1016/j. engstruct.2020.111326

33. Weertman, J. 2005. Stress and strain potentials for mode I and mode II cracks. Mechanics of Materials 37(5): 543-550. DOI: 10.1016/j.mechmat.2004.04.006

ZHIWEI GAO, DONGPO WANG, BAOMING GONG (gongbm@tju. edu.cn), CAIYAN DENG, and SHAOJIE WU are with Tianjin Key Laboratory of Advanced Joining Technology, School of Materials Science and Engineering, Tianjin University, Tianjin, China. HAI ZHANG is with the Aeronautical Engineering Institute, Civil Aviation University of China, Tianjin, China. 